\title{
Structural changes and variability of the ITCZ induced by radiation-cloud-convection-circulation interactions: inferences from the Goddard Multi-scale Modeling Framework (GMMF) experiments
}

\author{
William K. M. Lau' ${ }^{1} \cdot$ Kyu-Myong Kim² ${ }^{2}$ Jiun-Dar Chern¹ $\cdot$ W. K. Tao ${ }^{3} \cdot$ L. Ruby Leung ${ }^{4}$
}

Received: 10 May 2019 / Accepted: 23 September 2019 / Published online: 5 October 2019

(c) The Author(s) 2019

\begin{abstract}
In this paper, we have investigated the impact of radiation-cloud-convection-circulation interaction (RC3I) on structural changes and variability of the Inter-tropical Convergence Zone (ITCZ) using the Goddard Multi-scale Modeling Framework, where cloud processes are super-parameterized, i.e., explicitly resolved with 2-D cloud resolving models embedded in each coarse grid of the host Goddard Earth Observing System-Version 5 global climate model. Experiments have been conducted under prescribed sea surface temperature conditions for 10 years (2007-2016), with and without cloud radiation feedback in the atmosphere, respectively. Diagnostic analyses separately for January and July show that RC3I leads to an enhanced and expanded Hadley Circulation characterized by (1) a quasi-uniform warming and moistening of the tropical atmosphere and a sharpening of the ITCZ with enhanced deep convection, more intense precipitation and higher clouds, (2) extended drying of the tropical marginal convective zones, and extratropical mid- to lower troposphere, and (3) a cooling of the polar regions, with increased baroclinicity and midlatitude storm track activities. Computations based on the zonal mean thermodynamic energy balance equation show that the radiative warming and cooling are strongly balanced by local adiabatic processes associated with changes in large-scale vertical motions, as well as horizontal atmospheric heat transport. In the tropics, enhanced short-wave absorption and longwave water vapor greenhouse effects by high clouds play key roles in providing strong positive feedback to the tropospheric warming. In the extratropics, increased atmospheric heat transport associated with changes in the Hadley circulation is balanced by strong longwave cooling above, and warming below due to increased high clouds. We also find a strong positive correlation between daily and pentad heavy rain in the ITCZ core, and expansion of the drier zones coupled to a contraction of the highly convective zones in the ITCZ, indicating a strong tendency RC3I-induced convective aggregation in tropical clouds i.e., wet-regions-get-wetter and contracted, and dry-areasget-drier and expanded.
\end{abstract}

\section{Introduction}

Electronic supplementary material The online version of this article (https://doi.org/10.1007/s00382-019-05000-y) contains supplementary material, which is available to authorized users.

William K. M. Lau

wkmlau@umd.edu

1 Earth System Science Interdisciplinary Center, University of Maryland, College Park 20740, USA

2 Climate and Radiation Laboratory, NASA/Goddard Space Flight Center, Greenbelt, USA

3 Mesoscale Atmospheric Processes Laboratory, NASA/Goddard Space Flight Center, Greenbelt, USA

4 Pacific Northwest National Laboratory, Richland, USA
Differential solar and longwave radiative forcing, manifested as surplus in radiant energy in the tropics and deficit in polar regions, is well known to be the fundamental driver of the general circulation and the hydrologic cycle of the earth's climate system (Lorenz 1967; Wallace and Hobbs 1977). Rising motions in the moist atmosphere generate clouds, which interact with the large-scale circulation via feedback processes involving radiative transfer, phase changes, and convective processes (Stephens and Webster 1979; Stephens 2004). This interaction, hereafter referred to as radiation-clouds-convection-circulation-interaction (RC3I), further alters the heat and water balance, inducing changes 
in clouds, precipitation and circulation through dynamical adjustment processes, as the earth climate evolves around its quasi-equilibrium state. Dynamical adjustments are not limited to RC3I, but more generally represent responses and feedback to any internal or external forcing, that results in significant perturbation of the energy and water balance of the climate system. First and foremost, on the global scale, dynamical adjustments stemming from equator-to-pole differential radiative forcing give rise to the development and variability of large-scale atmospheric structures such as the Intertropical Convergence Zone (ITCZ), the Hadley and Walker circulations, mid-latitude storm tracks, and associated regional extreme precipitation. Dynamical adjustments involving the atmosphere, land, ocean, cryosphere, and biosphere can operate on diverse spatial and temporal scales, from diurnal, subseasonal-seasonal, interannual, inter-decadal to climate change (IPCC 2013).

One of the most prominent circulation features of the atmospheric general circulation is the ITCZ - a narrow band $\left(<10^{\circ}\right.$ latitude in width) of deep clouds spanning nearly the entire circumference of the equatorial regions. Even with the state-of-the-art climate models, simulations of the sharpness and the seasonal migration of the ITCZ remain a challenge (Zhang and Wang 2006; Lin 2007; Hwang and Frierson 2013; Li and Xie 2014; Byrne et al. 2018; Shonk et al. 2018; Landu et al. 2014; Bischoff and Schneider 2016; Xiang et al. 2017). Early climate modeling studies (Slingo and Slingo 1988, 1991; Randall et al. 1989), comparing control to nocloud-radiation experiments, have shown that overall RC3I warms and moistens the tropical atmosphere, enhances deep convection and precipitation in the ITCZ, and strengthens the Hadley Circulation (HC). Recent studies also have shown that anomalous cooling (warming) of the extratropics of the northern hemisphere leads to a southward (northward) shift of the ITCZ, with effects of cloud and water vapor radiation playing important roles (Broccoli et al. 2006; Kang et al. 2008; Frierson and Hwang 2012; Hwang and Frierson 2013). Other studies have indicated the importance of longwave radiative cooling in clear-sky or suppressed cloud regions in the tropics and subtropics in balancing the latent heating by deep convection in the ITCZ (Pierrehumbert 1995; Fu et al. 2002; Larson and Hartmann 2003; Mauritsen and Stevens 2015). More recent studies showed that uncertainties of the ITCZ structure in climate model and in idealized aquaplanetary simulations are strongly dependent not only on parameterization of convective processes, but also in model representation of cloud radiative processes (Voigt et al. 2014; Voigt and Shaw 2015, Talib et al. 2018). Tian (2015) showed that bias in model climate sensitivity to global warming maybe traced to similar bias in model simulation of the ITCZ. However, the role of cloud radiation in modulating ITCZ convection, precipitation, large-scale circulation and associated atmospheric heating/cooling processes are still unclear. Bony et al. (2015) argued that cloud radiation feedback in convective organization, and ITCZ structure and variability are two of the top four most pressing knowledge gaps in climate science (the other two being extratropical storm track variability, and convective self-aggregation) that will have the best chance to be filled in the near future, with significant benefits to society, provided the scientific community can devote focused and coordinated efforts in maximizing the use of available modeling tools and observations. As apparent later in this paper, our results show that these four key research areas in climate sciences are closely intertwined. Specifically, extratropical storm track variability and convective aggregation are components of a global dynamical adjustment, linked, to structural changes of the ITCZ and cloud radiation feedback induced by RC3I.

Analyses of long-term satellite derived rainfall have revealed tantalizing hints that there has been a long-term increase in rainfall, i.e., enhanced latent heating in the ITCZ of the equatorial central and eastern Pacific since 1979 (Lau and $\mathrm{Wu}$ 2007, 2011; Gu and Adler 2013; Tan et al. 2015; Gu et al. 2016). In addition to the increased ITCZ precipitation, a multi-decadal trend indicating a narrowing of the ITCZ in the central and eastern equatorial Pacific has been observed (Zhou et al. 2011; Wodzicki and Rapp 2016). Contemporaneously, observational studies have found evidence of global warming in multi-decadal trend in a widening of the subsidence zone of the HC (Hu and Fu 2007; Seidel and Randel 2007; Lu et al. 2009), as well as a drier, and poleward expansion of the subtropical arid land regions in the last three decades (Dai 2011, 2013; Feng and Fu 2013; Huang et al. 2017). The observed sharpening of the ITCZ convective core and the drying in the subtropics are likely to be connected to a canonical pattern of changes in global precipitation characteristics, linked by the dynamical adjustments of the general circulation in response to greenhouse warming (Lau et al. 2013). However, the mechanisms of the ITCZ narrowing and intensification, as well as connection to widening and drying are still not well understood. Lau and Kim (2015) based on analyses of CMIP5 models, found evidence of a planetary scale dynamical adjustment mechanism under greenhouse warming, i.e., the Deep Tropical Squeeze (DTS), which posits that dynamical feedback associated with increased latent heating in deep convection in the ITCZ can spur an intensification and a narrowing of the ascending branch of the HC, coupled to a rise of the level of maximum outflow of the HC, and increased drying and widening of the descending branch of the HC. Others have suggested that the narrowing of the ITCZ stems from increasing meridional gradient of moist static energy between the tropics and extratropics, and that atmospheric dynamics contribute substantially to all-sky and cloud radiative feedback in the tropics, but are relative less important at higher latitudes (Byrne and Schneider 2016, 2018; Byrne et al. 2018). Still others have found evidences 
from CMIP5 model analyses and aqua-planet simulations that RC3I may play important roles in changing clouds and precipitation efficiency in the ITCZ, in connection to changes in the large-scale circulation (Su et al. 2014, 2017; Zhao 2014; Voigt et al. 2014; Voigt and Shaw 2015; Harrop and Hartman 2016). While a scientific consensus has yet to emerge regarding the relative importance of the myriad processes giving rise to changing structures of ITCZ and the large-scale circulation, there is little double that all studies point to the need for a better understanding of fundamental processes governing RC3I.

The objective of this work is to provide, using climate model simulation, a more fundamental understanding of the effects of RC3I on structural changes of the ITCZ and associated changes in the large-scale circulation, clouds and precipitation, including aspects of convective aggregation, from the perspective of cloud radiation effects on diabatic heating processes, and energy balance of the global atmosphere.

\section{Model description and experimental design}

This study is based on numerical experiments using the Goddard Multi-scale Modeling Framework (GMMF), which consists of a coupling of the Goddard Cumulus Ensemble model (GCE) and the Goddard Earth Observing SystemVersion 5 (GEOS-5) global atmospheric model (Tao et al. 2014). The GMMF belongs to the class of global climate model, often referred to as super-parameterized global climate model (SP-GCM), where the subgrid-scale cumulus parameterization schemes are replaced by two-dimensional cloud resolving models at high-resolution $(2-4 \mathrm{~km})$, embedded in the coarse resolution (100-250 km) GCM grids (Randall et al. 2003; Khairoutdinov et al. 2005, 2008; Tao et al. 2009; Li et al. 2012; Chern et al. 2016). Because of the more realistic representation of cloud microphysical processes by resolving convection at high resolution, SP-GCMs have been used in a variety of studies on multi-scale interactions involving radiation, cloud-scale convection and circulation on scales from diurnal to climate change (Luo and Stephens 2006; Marchand et al. 2009; Pritchard and Somerville 2009; Pritchard et al. 2011; Tao and Chern 2017).

For the present study, we used the recently updated GMMF Version 2.0, configured to run with $2^{\circ} \times 2.5^{\circ}$ (latitude $\times$ longitude) horizontal grid spacing in the host GEOS5 GCM. Embedded in each GEOS-5 grid column, is a 64-column two-dimensional GCE with a horizontal spacing of $4 \mathrm{~km}$, running with a $10 \mathrm{~s}$ time step with cyclic lateral boundaries (Tao et al. 2009; Chern et al. 2016). GMMFVersion 2.0 includes several important improvements compared to previous versions. Briefly, the vertical layers within the GEOS model and GCE are increased to 48 and
44 respectively, with higher resolution in the lower atmosphere (17 layers below $700 \mathrm{hPa}$ ) to better represent boundary layer cloud processes. The GCE model top height has been extended, raising the lowest damping level upward from 16 to $20 \mathrm{~km}$ to allow for highly penetrative deep convection. Fully compressible dynamics (Klemp and Wilhelmson 1978) are used instead of the anelastic flow (Ogura and Phillips 1962) used previously. The radiation code is called from the embedded GCE to get better cloud radiation interaction at the natural temporal and spatial resolution of clouds (Chern et al. 2016). Both longwave and shortwave radiation calculations include improved schemes for absorption due to water vapor, $\mathrm{O}_{3}, \mathrm{O}_{2}, \mathrm{CO}_{2}$, minor trace gas $\left(\mathrm{N}_{2} \mathrm{O}, \mathrm{CH}_{4}\right.$, and $\mathrm{CFCs}$ ), clouds, and aerosols, as well as scattering by clouds, aerosols, molecules (Rayleigh scattering), and the surface (Chou et al. 1999, 2002; Chou and Suarez 1999). Radiative fluxes are integrated over nearly the entire spectrum, including eight bands in the ultraviolet and visible region and three in the infrared region. Most important for this study, GMMF Version 2.0 includes a new four-class ice scheme (cloud ice, snow, graupel, and frozen drops/hail) with capabilities that include: ice supersaturation microphysics, depositional growth of cloud ice to snow, varying cloud ice fall speeds, limiting cloud ice particle size, and new size-mapping schemes for snow and graupel (Lang et al. 2014; Tao et al. 2016). The 4ICE scheme produces better overall spatial distribution of cloud ice amount, total cloud fractions, net radiation, and total cloud radiative forcing than earlier threeclass ice schemes compared to observations from CloudSat/ CALIPSO and radar data (Chern et al. 2016). Since graupel and frozen drops/hail can simultaneously occur in nature both in the same storm and in different storm systems at different locations, a 4ICE scheme is necessary to simulate the diverse array of cloud systems over the entire globe. Version 2.0 also includes an improved land surface model (Mohr et al. 2013) that has been computationally enhanced for high impact weather studies (Shen et al. 2013).

Worth noting is that the configuration of the GMMF v. 2 used for our model simulations contains 13,100 copies of $2 \mathrm{D}$ cloud resolving models at $4 \mathrm{~km}$ horizontal resolution covering the entire globe, running on a time step of $10 \mathrm{~s}$, coupled to the GEOS5 global model on a $2 \times 2.5$ lat-long grid and complex physics packages running at 1-h time step. As a result, while the use of GMMF for multi-scale interaction studies represents a clear advantage over GCM with parameterized subgrid scale convection, and considerable saving compared to running cloud resolving models globally (Satoh et al. 2008), computation resources for running the GMMF and storing outputs from the experiments are still very demanding. Computation resource is an important consideration in deciding on the following experimental design.

As a first step in our use of GMMF to investigate cloud radiative feedback processes on ITCZ, the experiment design 
in this study is aimed at identifying the roles of atmospheric processes only, i.e., RC3I, but not surface feedback. Surface processes over land and ocean are known to provide important climate feedback (Qu and Hall 2006; Andrew et al. 2009; Lloyd et al. 2012; Stephens et al. 2018), and their modulation of RC3I is a subject of an ongoing investigation outside the scope of this study. Here, in the control experiment (Control), the GMMF v.2.0 was integrated with full atmospheric physics, including cloud radiative feedback, interactive land, under prescribed sea surface temperature forcing for 10 years (2007-2016). For the anomaly experiment (NoCRF), the same experiment as Control was conducted, except (a) the cloud optical thickness was set to zero in the radiative code, and (b) all surface heat fluxes including net shortwave and long-wave radiation, sensible and latent heat from the land surface to the atmosphere were restored to those of the hourly values of Control at every GEOS5 time step, i.e., the land surface model is essentially turn off. Step b) is necessary to prevent climate drift in NoCRF due to fast feedback of land processes. Clouds are still generated in NoCRF by the embedding cloud resolving models, except that the cloud radiative (both shortwave and longwave) effects are turn off. Due to the prescribed land surface fluxes, there are some energy imbalance at the lowest layer of the atmosphere in NoCRF that the atmosphere will have to adjust to at every GCE (10 s) and every GCM (1 h) time step. The imbalance result in a sharpening of the climatological precipitation diurnal cycle over land i.e., approximately $10-20 \%$ increase in the daily maximum in late afternoon, slight decrease at other times of the day, but no significant diurnal cycle change over the ocean, in NoCRF compared to Control (see Fig. S1). Given that the focus of our study is on changing structure of ITCZ precipitation which is mostly over the ocean, the nearly identical climatologival precipitation diurnal cycle over the ocean between Control and NoCRF provides assurance that the impact of the imbalance on our results is not likely to be too large.

Because of the relatively fast time scales of atmospheric adjustment processes in GMMF, the results of the 10-year integration are reasonably stable, with all the climatological heating and cooling processes in quasi-equilibrium. Differences in various dynamic and thermodynamic quantities between the control and NoCRF (Control-minus-NoCRF) will be referred to as anomalies induced by RC3I in the following discussion.

\section{Results}

Because the ITCZ migrates seasonally to and away from the equator every year, change in the structure due to RC3I such as the narrowing or sharpening of the ITCZ, may be masked by the seasonal movement, or changes in the seasonal movement of the ITCZ. To better delineate the fundamental changes in the ITCZ structure due to RC3I, we have conducted analyses separately for January and July, where the ITCZ is at approximately the same location respectively every year, and at its maximum strength. All analyses for January have been repeated for July. Results indicate that key features in July are very similar to January, except for the magnitude, the location of the ITCZ, and a switch of more dynamically active (winter) hemisphere to the southern hemisphere. To avoid repetition, most results for July are shown only in the Supplementary Information (SI). A summary description, comparing salient RC3I features, with respect to ITCZ structural changes, and convective aggregation for January and July are included in Sect. 4.

\subsection{Changes in temperature, moisture, precipitation and circulation}

To begin, we compare the global climatological 10-year (2007-2016) mean January precipitation to TRMM observations for the same years. To facilitate discussion, we define the ITCZ domain as the region within $30^{\circ} \mathrm{S}-30^{\circ} \mathrm{N}$ where the monthly mean precipitation exceeds $6 \mathrm{~mm} \mathrm{day}^{-1}$. The climatological GMMF model global precipitation compare well to the TRMM observation, in terms of the location and width of the ITCZ domain and the mid-latitude storm tracks, except that model over-estimates peak ITCZ precipitation rate by approximately 20-30\% compared TRMM (Fig. 1a). The over-estimation of tropical precipitation appears to be a common feature of SP-GCMs, likely due to the inherent limited degree of atmospheric motions in embedding 2-D CRMs with cyclic boundary conditions, i.e., inability for deep convective system to propagate to neighboring GCM grids, and the singular orientation of convection that could bias momentum transport by convection (Randall et al. 2003; Khairoutdinov et al. 2005; Cheng and Xu 2011). From the difference maps (Fig. 1b-d), a substantial change in the general circulation can be discerned. During January, RC3I enhances precipitation in the ITCZ core located near $5-8^{\circ} \mathrm{S}$, reduces precipitation near the boundaries of the ITCZ, including regions of the South Africa, Northeastern Australia, and South America (Fig. 1b). Precipitation over the subtropical and extratopical storm track regions of the North Pacific, North Atlantic, and the South Pacific Convergence Zone are also enhanced. These features are manifested in the zonal mean as a sharpening of the ITCZ, i.e., enhanced precipitation in the ITCZ core near the equator and reduced precipitation on its flanks (Fig. 1b, right panel), consistent with the "deep tropical squeeze" (Lau and Kim 2015), and the "upped-ante" mechanism (Neelin et al. 2003; Chou and Neelin 2004; Lintner and Neelin 2007). This change in the ITCZ structure is coupled to enhanced precipitation in the midlatitudes associated with changes in 

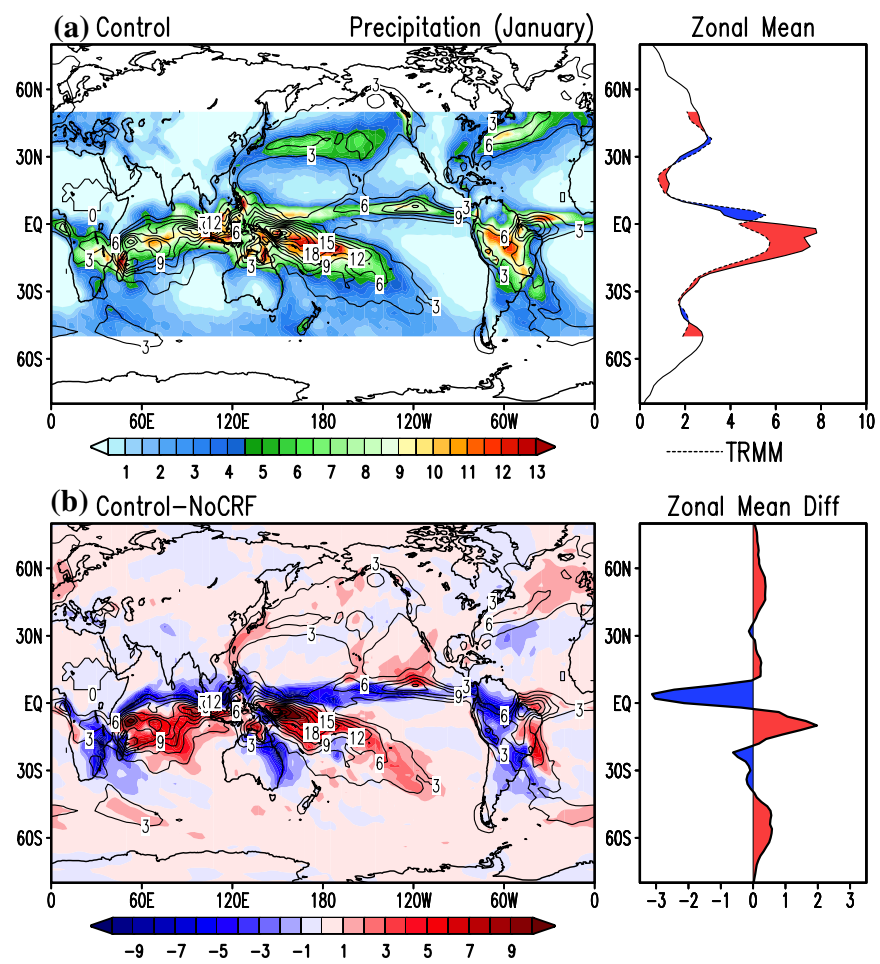

Fig. 1 Spatial distribution of a climatological (2001-2010) precipitation $\left(\mathrm{mm} \mathrm{day}^{-1}\right)$ for the model control (contoured) and for TRMM, and $\mathbf{b}$ climatological precipitation difference (control-minus-NoCRF). Zonal mean profiles are shown on the right subpanels. $\mathbf{c}, \mathbf{d}$ are the

the subsiding and extended branches of the HC. The global precipitation anomalies are associated with a near-uniform warming of the mid-troposphere in the tropics, and cooling at polar latitudes $\left(60^{\circ}-90^{\circ}\right)$ in both hemispheres, with the cooling more pronounced in the northern (winter) hemisphere (Fig. 1c). The differential warming/cooling creates zones of increased baroclinicity in the extratropics $\left(30-60^{\circ} \mathrm{N}\right.$ and $35-60^{\circ} \mathrm{S}$ ) of both hemispheres (Fig. 1c, right panel), enhancing midlatitude storm track activities over the oceanic areas in both hemispheres, and western regions of continents of the northern hemispheres (Fig. 1d).

The RC3I-induced warming in the tropics and cooling in polar regions represent substantial global perturbation to the thermal structure of the atmosphere, extending from the lower troposphere to the upper troposphere and lower stratosphere (UTLS, 200-100hpa), where the temperature gradient are most pronounced in the northern (winter) hemisphere near the polar edge $\left(30-45^{\circ} \mathrm{N}\right)$ of the subsiding branch of the HC (Fig. 2a, b). The sharpening of the ITCZ is reflected in enhanced ascent in the rising branch of the $\mathrm{HC}$ near $5-10^{\circ} \mathrm{S}$, coupled to strong anomalous sinking motion, at approximately $5^{\circ}$ north of the equator. Also found are regions of alternating anomalous ascent and descent in the subtropics and extratropics, featuring increased subsidence near poleward edges of the subsiding branches of the $\mathrm{HC}$, and overall
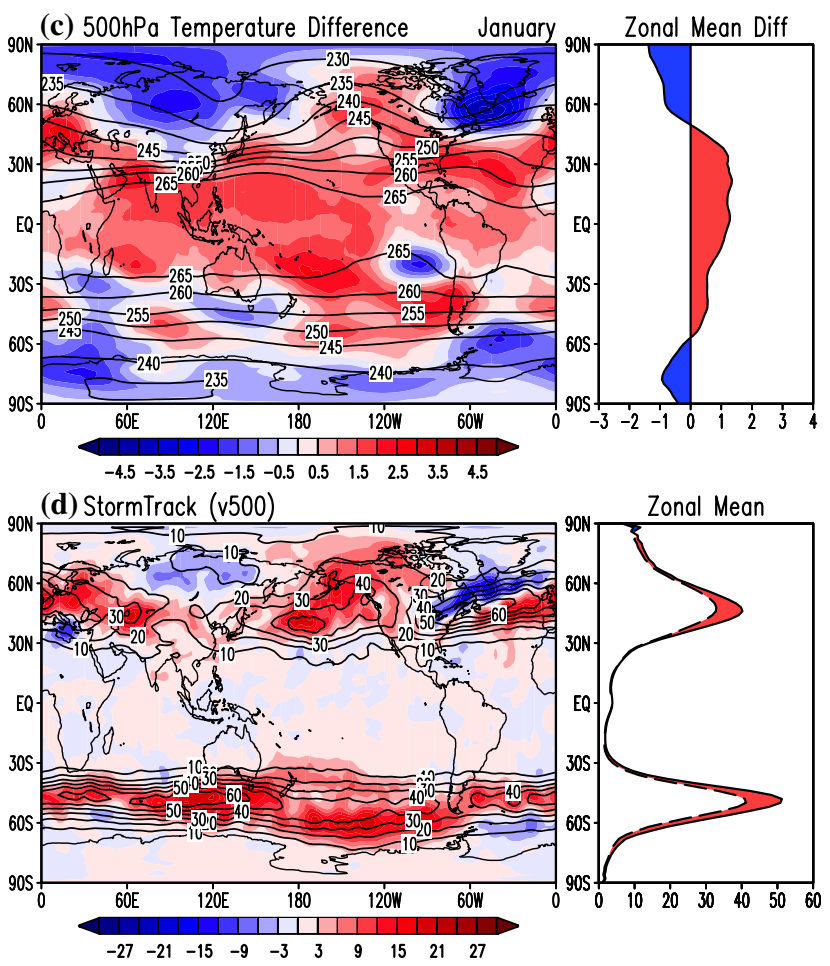

same as in b, except for $500 \mathrm{hPa}$ temperature $\left({ }^{\circ} \mathrm{K}\right)$, and storm track activities represented by the mean square variances of the zonal mean deviations of the meridional winds $\left(\mathrm{m}^{2} \mathrm{~s}^{-2}\right)$ at $500 \mathrm{hPa}$

weakly enhanced ascent in the Ferrel cell at high latitudes $\left(40-90^{\circ} \mathrm{N}, \mathrm{S}\right)$, consistent with the moderate increase in zonal mean precipitation there (see Fig. 1b, right panel). Strong anomalous cross-equatorial flow from the southern hemisphere $(\mathrm{SH})$ to the northern hemisphere $(\mathrm{NH})$ is found in the upper troposphere, coupled to strong return flow in the lower troposphere and near the surface (Fig. 2c). Noting that $\mathrm{NH}$ is anomalously colder due to RC3I compared to the $\mathrm{SH}$, the direction of the cross-equatorial meridional flow is consistent with the notion that the ITCZ ascending branch tend to stay and enhanced in the warmer hemisphere ( $\mathrm{SH}$ in January), in order to allow for heat balance by atmospheric transport to ameliorate excessive cooling at higher latitudes (Broccoli et al. 2006; Kang et al. 2008; Frierson and Hwang 2012). As indicated earlier (Fig. 1d), and discussed in more details later based on component contributions using the thermodynamic energy equation, storm track activities effecting poleward heat transport are strongly enhanced in the extratropics due to RC3I. In conjunction with the aforementioned changes in the overturning circulations, there is substantial moistening (increased specific humidity, q) and drying (decreased q) of the tropical atmosphere coinciding with the regions of anomalous ascent and descent, respectively (Fig. 2d). Also noticed is that the polar regions $\left(>60^{\circ} \mathrm{N}\right.$, and $\left.\mathrm{S}\right)$ of both hemispheres are generally 
(a) Temperature

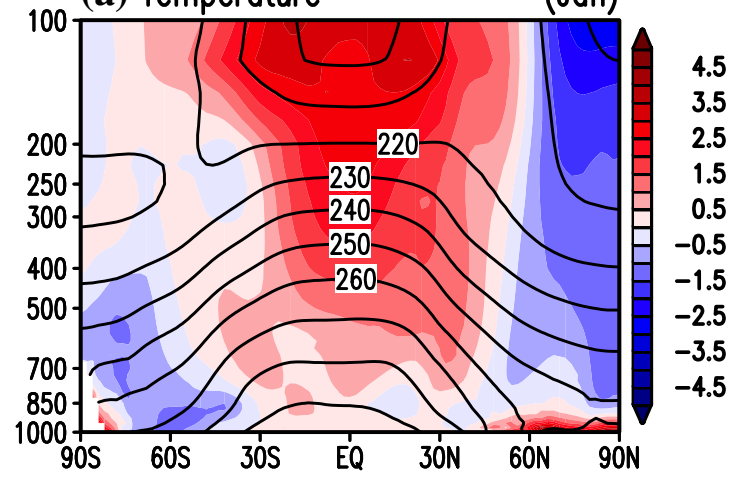

(c) Meridional winds

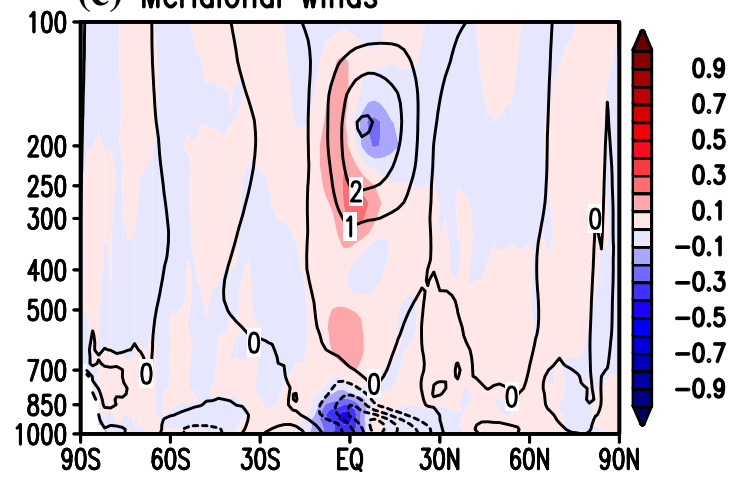

(e) Relative humidity

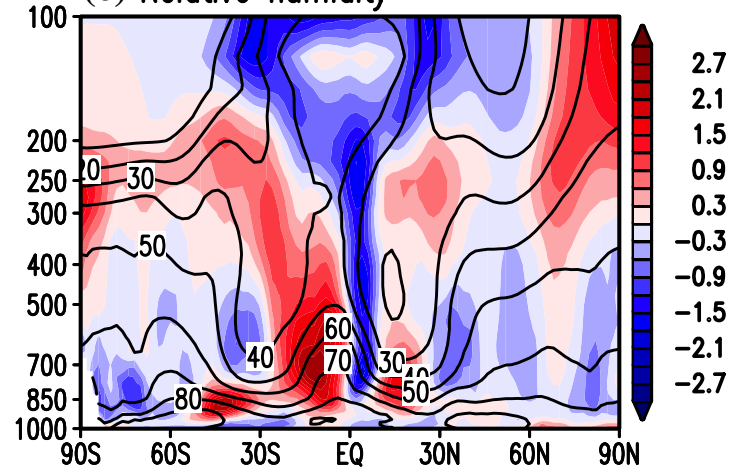

Fig. 2 Height-latitude cross-sections of a temperature $\left({ }^{\circ} \mathrm{K}\right)$, b negative p-velocity $\left(\mathrm{hPa} \mathrm{s}^{-1}\right)$, c merdional winds $\left(\mathrm{ms}^{-1}\right)$, $\mathbf{d}$ specific humidity $\left(\mathrm{g} \mathrm{kg}^{-1}\right)$, e relative humidity $(\%)$, and $\mathbf{f}$ cloud water $\left(\mathrm{mg} \mathrm{kg}^{-1}\right)$. Control-minus-NoCRF values are shaded and NoCRF values contoured. In b solid (dotted) contours denote rising (sinking) climato-

drier, in connection of the development of colder temperature there. However, atmospheric convection states are not solely controlled by moisture abundance, but more strongly controlled by relative humidity $R_{h}$, which are dependent on both thermodynamic and dynamics. Based on the ClausiusClapeyron relationship $\mathrm{dR}_{\mathrm{h}}=\mathrm{dq} / \mathrm{qs}-\alpha \mathrm{R}_{\mathrm{h}} \mathrm{dT}$, where $\alpha=6.5 \%$ $\mathrm{K}^{-1}$, an increase in specific humidity will enhance $\mathrm{R}_{\mathrm{h}}$, but an increase in temperature will reduce $R_{h}$. Furthermore, atmospheric advective processes, stemming from anomalous subsidence bringing drier air from aloft, can also lead to reduced $R_{h}$ in mid- and lower troposphere. Hence, changes

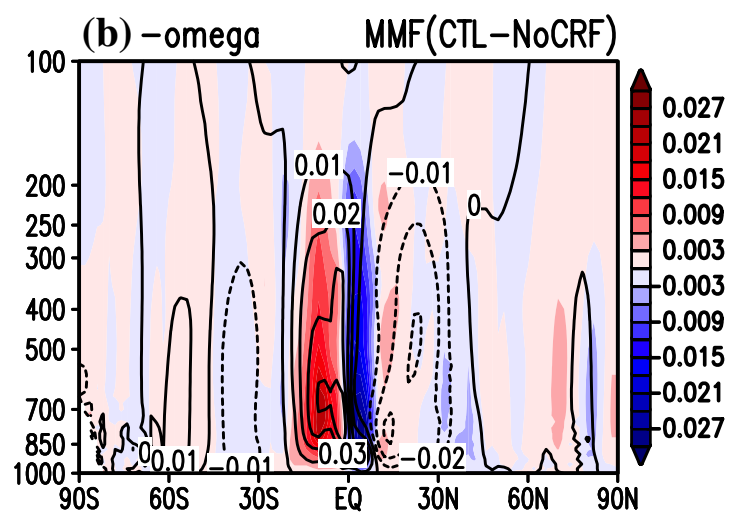

(d) Specific humidity

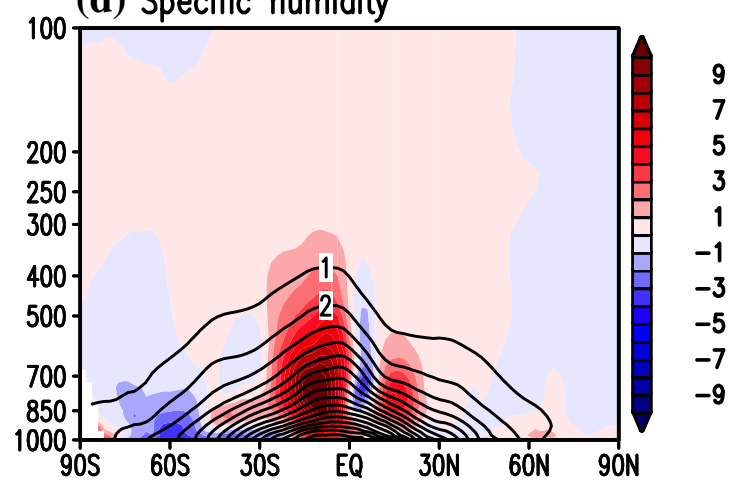

(f) Cloud (Ice+Liquid)

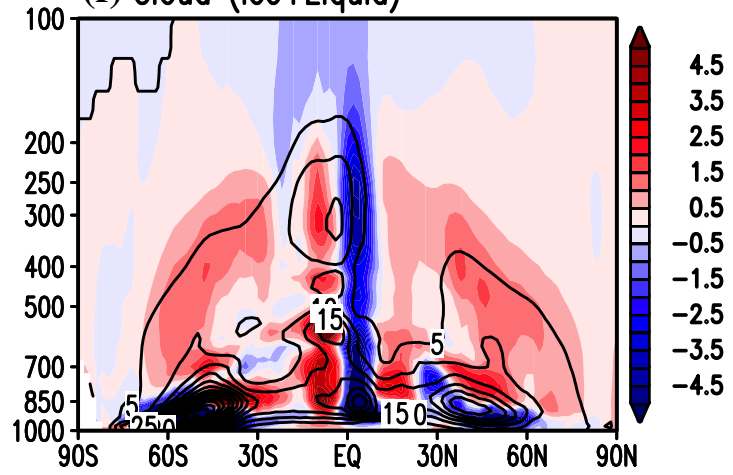

logical motion; positive deviations (red) denote anomalous rising motion, and negative deviations (blue) denote anomalous sinking motion. The same color code, positive (red), and negative (blue) applies to anomalies in specific humidity, RH and cloud water

in $\mathrm{R}_{\mathrm{h}}$ represent the competing effects of changes in $\mathrm{q}, \mathrm{T}$ and vertical motions (Fig. 2e). These effects give rise to strong $\mathrm{R}_{\mathrm{h}}$ increase (decrease) in regions with strong anomalous ascent (descent) in the tropics, and mostly decreased $\mathrm{R}_{\mathrm{h}}$ in the mid-and lower troposphere of the subtropics and polar region. In the upper troposphere lower stratosphere (UTLS, 200-100 hPa), where convective moisture transport is limited, change in $R_{h}$ is mostly controlled by temperature effect, i.e., the warmer (the colder), the stronger decrease (increase) in $\mathrm{R}_{\mathrm{h}}$. Likewise, cloud water (liquid $+\mathrm{ice}$ ) is strongly increased (decreased) in the anomalous ascending 
(descending) region of the deep tropics (Fig. 2f). The large reduction in cloud ice over extensive areas in the UTLS of the tropics and extratropics $\left(60^{\circ} \mathrm{S}-60^{\circ} \mathrm{N}\right)$ is due to the large reduction in relative humidity associated with the much warmer temperature over this region. Elsewhere, in the subtropics and midlatitudes $\left(30-60^{\circ} \mathrm{N}, \mathrm{S}\right)$, a reduction in boundary layer (1000-850 $\mathrm{hPa}$ ) cloud water and increase in mid- to high clouds (850-300 hPa) signals a lifting of the clouds with more abundance of high clouds and increased precipitation over these regions. This is due respectively to the drying of the lower troposphere from mean circulation and temperature change, as well as enhanced poleward transport of heat and moisture in the mid- and upper troposphere associated with the increased storm track activities. Overall the aforementioned features signal an enhanced $\mathrm{HC}$ with extended influences on the extratropics due to RC3I (See further discussion in next section).

\subsection{Diabatic heating and dynamical tendencies}

In this section, we examine the RC3I-induced changes in the heat balance of the atmosphere via the thermodynamic energy equation

$\frac{\partial \bar{s}}{\partial t}+\overline{v^{\prime} \cdot \nabla s^{\prime}}+\overline{\omega^{\prime} \frac{\partial s^{\prime}}{\partial p}}=Q_{M P}+Q_{R}-\nabla \cdot \overline{s^{\prime} v^{\prime}}-\overline{\frac{\partial s^{\prime} \omega^{\prime}}{\partial p}}$,

which can be re-written as:

$\frac{\partial \bar{s}}{\partial t}=Q_{D Y N}+Q_{M P}+Q_{S W}+Q_{L W}=0$ for steady state balance.

In Eq. (1), the overbar represents monthly mean, and the prime daily deviations from the mean, $s=\left(\mathrm{C}_{\mathrm{p}} \mathrm{T}+\mathrm{gz}\right)$ is the dry static energy, $\mathrm{Q}_{\mathrm{MP}}$ represents moist heating associated with condensation, evaporation, deposition and sublimation, freezing and melting processes in liquid and/or ice-phase precipitation derived from the embedding GCEs, and $Q_{R}$ is the radiative heating. Both $\mathrm{Q}_{\mathrm{MP}}$ and $\mathrm{Q}_{\mathrm{R}}$ are computed within the GCE codes, and translated onto the GEOS5 coarse grids. In Eq. (2), $Q_{D Y N}=-\left(\overline{v^{\prime} \cdot \nabla s^{\prime}}+\overline{\omega^{\prime} \frac{\partial s^{\prime}}{\partial p}}\right)-\left(\nabla \cdot \overline{s^{\prime} v^{\prime}}+\frac{\partial \overline{s^{\prime} \omega^{\prime}}}{\partial p}\right)$ represents the dynamic tendency, and $Q_{R}$ is further decomposed into heating by shortwave $\left(\mathrm{Q}_{\mathrm{SW}}\right)$ and longwave $\left(\mathrm{Q}_{\mathrm{LW}}\right)$ radiation. Each of the heating terms in Eq. (2) has been computed for Control and NoCRF respectively. In Control climatology, in the deep tropics and near the ITCZ core, there is a strong local balance between $\mathrm{Q}_{\mathrm{MP}}$ and $\mathrm{Q}_{\mathrm{DYN}}$ (adiabatic cooling of ascending air) in the troposphere up $200 \mathrm{hPa}$ (Fig. 3a, b), in accord with the well-known weak temperature gradient approximation of the tropical atmosphere (Sobel et al. 2001; Raymond and Zeng 2005). In mid-latitudes $\left(30-60^{\circ} \mathrm{N}\right.$, and $\left.30-60^{\circ} \mathrm{S}\right)$, heating by $\mathrm{Q}_{\mathrm{MP}}$ associated with storm track is strong, but with shallower heating profile compared to the deep tropics (Fig. 3a). $\mathrm{Q}_{\text {DYN }}$ heats the atmosphere in the subsidence branch of the HC through adiabatic warming of descending air, and in the mid-latitude and polar regions, by poleward heat transport via transient and stationary eddies associated with storm tracks (Fig. 3b). However, strong cooling in the tropics and warming in the northern (winter) hemisphere by $\mathrm{Q}_{\mathrm{DYN}}$ are not balanced by $\mathrm{Q}_{\mathrm{MP}}$ above $200 \mathrm{hPa}$ because climatologically convection rarely reaches such high altitudes. The net cooling and heating imbalance in the UTLS implies a net transport of heat by $\mathrm{Q}_{\mathrm{DYN}}$ from tropics to extratropics. This is evidenced in the pattern of the sum of $\mathrm{Q}_{\mathrm{MP}}$ and $\mathrm{Q}_{\mathrm{DYN}}$ (Fig. 3c), which can be interpreted as the net atmospheric heat transport (AHT) after the local heating/cooling balance by $\mathrm{Q}_{\mathrm{MP}}$ and $\mathrm{Q}_{\mathrm{DYN}}$ has been accounted for. Here, it is clear that the overall effect of AHT is to transport solar radiation absorb near earth surface to the lower and mid-troposphere, and from the tropics to higher latitudes. The AHT impact on the UTLS is most pronounced in the northern hemisphere, likely due to enhanced upward propagation of wave energy by transient as well as quasi-stationary planetary scale waves during boreal winter (Charney and Drazin 1961; Simmons 1974; Holton 2004). For steady state, the AHT must be balanced by the total radiative heating $Q_{R}$ (Fig. 3d). Here, $Q_{R}$ shows a pattern almost exactly opposite to that AHT, with a magnitude difference less than a few percent. A breaking down of $Q_{R}$ into $\mathrm{Q}_{\mathrm{SW}}$ and $\mathrm{Q}_{\mathrm{LW}}$ (Fig. 3e, f) shows clearly that $\mathrm{Q}_{\mathrm{LW}}$ is the dominant process, highly inversely correlated with AHT. $\mathrm{Q}_{\mathrm{SW}}$ contributes to warming of the troposphere in the southern (summer) hemisphere, but has little or no contribution to the northern (winter) hemisphere due to low inclination of the sun. These results provide assurance that that physical processes governing the general circulation, convection, precipitation and clouds in GMMFv.2.0 are reasonably realistic, and consistent with fundamental conservation principles for atmospheric heat balance (Peixoto and Oort 1992).

The sharpening of the ITCZ induced by RC3I can be identified with the strong increase in anomalous $\mathrm{Q}_{\mathrm{MP}}$ at the ITCZ core about $5^{\circ}$ south of equator, and decrease on both its flanks (Fig. 4a). Moderate positive $\mathrm{Q}_{\mathrm{MP}}$ with lower scale height associated with enhanced storm track activities can also be found in the extratropics of both hemispheres. Through adiabatic cooling (warming) of the ascending (descending) air, $\mathrm{Q}_{\mathrm{DYN}}$ provides strong balance to the $\mathrm{Q}_{\mathrm{MP}}$ warming/cooling in the ITCZ region (Fig. 4b), as well as heat transport from tropics to extratropics. The AHT (Fig. 4c) indicates increasing heat transport from the tropics to extratropics and polar latitudes in the lower to mid-troposphere, reflecting an intensification of the HC and increased storm track activities in the extratropics. In the UTLS, the strong AHT cooling in the northern hemisphere polar region signals a reduction of the upward propagation of planetary scale wave into the lower stratosphere 
Fig. 3 Height-latitude crosssections of climatological control of a moist heating processes $\mathrm{Q}_{\mathrm{MP}}, \mathbf{b}$ dynamical tendencies $\left(\mathrm{Q}_{\mathrm{DYN}}\right)$, c atmospheric heat transport (AHT), $\mathbf{d}$ radiative heating $\left(Q_{R}\right)$, e shortwave heating $\mathrm{Q}_{\mathrm{SW}}$, and $\mathbf{f}$ longwave heating $\left(\mathrm{Q}_{\mathrm{SW}}\right)$. Unites are in $\mathrm{K} \mathrm{day}^{-1}$
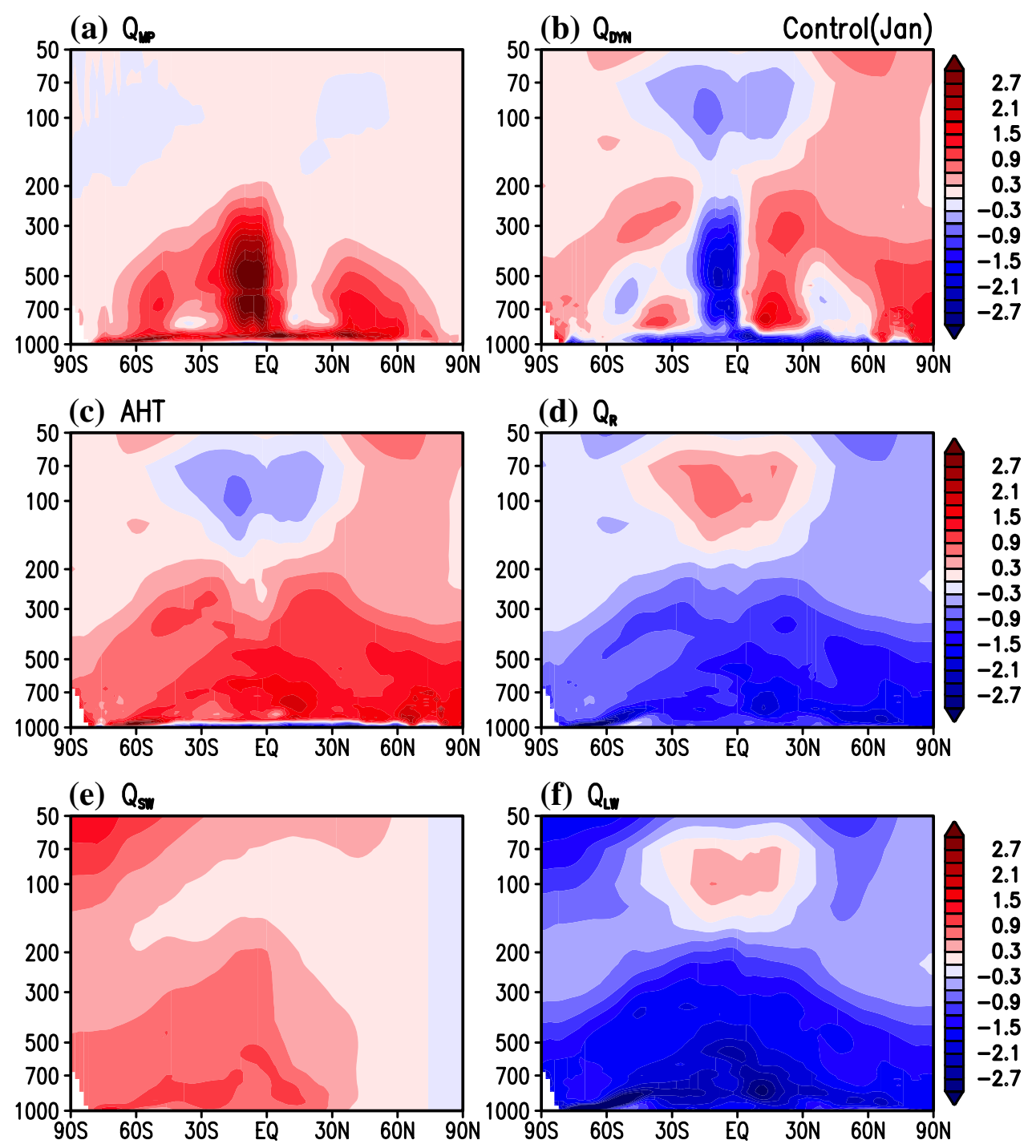

(See Fig. 3c). The anomalous $Q_{R}$ pattern (Fig. 4d) shows almost identical features as AHT everywhere except with the sign switched, indicating a high degree of balance between $Q_{R}$ and AHT. A decomposition of $Q_{R}$ shows that $\mathrm{Q}_{\mathrm{SW}}$ (Fig. 4e) contributes significantly to the heating of the upper troposphere in the tropics of the southern (summer) hemisphere. Here, the upper-level $\mathrm{Q}_{\mathrm{SW}}$ heating is likely contributed by high (ice) clouds via increased absorption of near-infrared SW radiation, and enhanced absorption by increased super-cooled water, while opposed by cooling below clouds due to increased ice cloud scattering of SW radiation (Randall et al. 1989, Hong et al. 2016). On the other hand, $\mathrm{Q}_{\mathrm{LW}}$ (Fig. 4f) contributes to warming below clouds via the trapping of increased water vapor and cloud droplet, i.e., greenhouse effect, leading to strong warming below clouds in the tropics. Together $\mathrm{Q}_{\mathrm{LW}}$ and $\mathrm{Q}_{\mathrm{SW}}$ maintain a strong column heating by $\mathrm{Q}_{\mathrm{R}}$ (Fig. 4d) in the ITCZ region $\left(10^{\circ} \mathrm{S}-5^{\circ} \mathrm{N}\right)$, providing positive feedback to $\mathrm{Q}_{\mathrm{MP}}$.
In the extratropics, ice and mixed-phase high clouds are formed at increasing lower elevations at higher latitudes due to lower climatological tropospheric temperature. As a result, $\mathrm{Q}_{\mathrm{LW}}$ displays a characteristic downward sloping pattern towards the polar region, with cooling above and warming below clouds due to increased greenhouse effect of water vapor and cloud water (Lacis and Hansen 1974; Stephens 2004). Near surface warming and cloud top cooling due to low clouds can also be seen in the lower troposphere below $700 \mathrm{hPa}$ (Fig. 4f). Overall, $\mathrm{Q}_{\mathrm{LW}}$ provides the substantial balance to the AHT heating/cooling due to large-scale dynamical adjustment. The close relationship between variability of outgoing longwave radiation and atmospheric diabatic heating components has been noted from studies using reanalysis and satellite data products (Zhang et al. 2017). 
Fig. 4 Same as in Fig. 3, except for Control-minus-NoCRF
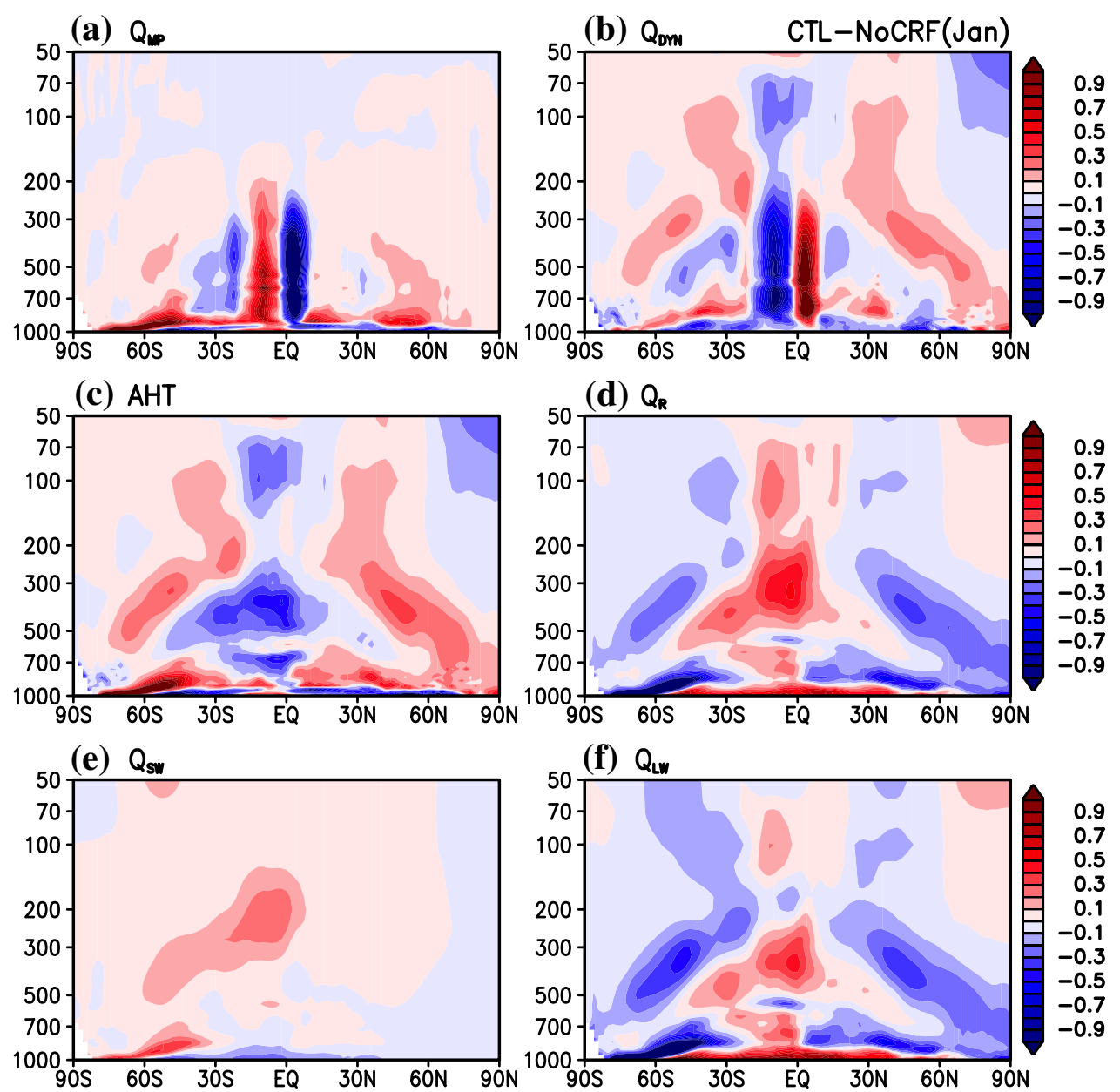

\subsection{Cloud-radiation-precipitation feedback in the tropics}

In this subsection, we examine in more detail, functional relationships between RC3I-induced changes in precipitation and heating components that underpin the structural change in the ITCZ, described previously. Vertical crosssections of the heating components averaged over the tropics $\left(30^{\circ} \mathrm{S}-30^{\circ} \mathrm{N}\right)$, as a function of precipitation have been constructed. Figure 5a shows that strong positive $\mathrm{Q}_{\mathrm{MP}}$ induced by RC3I is associated with heavy precipitation and deep convection over the ITCZ core region $\left(\mathrm{P}>10 \mathrm{~mm} \mathrm{day}^{-1}\right)$ while weak but widespread reduction in $\mathrm{Q}_{\mathrm{MP}}$ is found over marginal convective zone (MCZ: $1<\mathrm{P}<10 \mathrm{~mm} \mathrm{day}^{-1}$ ) and the dry zone $\left(\mathrm{DZ}, \mathrm{P}<1 \mathrm{~mm}^{-1 a y}{ }^{-1}\right)$. Clearly, $\mathrm{Q}_{\mathrm{MP}}$ is largely balanced by cooling (warming) via adiabatic ascent (descent) in $\mathrm{Q}_{\mathrm{DYN}}$, as evidenced in the near-mirror image of two heating components (Fig. 5a, b). AHT (Fig. 5c), represented by the sum of $\mathrm{Q}_{\mathrm{MP}}$ and $\mathrm{Q}_{\mathrm{DYN}}$, indicates a net heat loss (cooling) in the ITCZ core region, and net transport of heat from the ITCZ to the drier regions in the UTLS region (warming), and an uptake of heat (warming) in the lower troposphere from the surface in the DZ. The near mirrorimage of the warming/cooling pattern in $\mathrm{Q}_{\mathrm{R}}$ (Fig. 5d) compared to AHT (Fig. 5c) reflects a new quasi-equilibrium induced by RC3I, involving enhanced radiative heating by high clouds in the ITCZ core region and low-level cooling in surrounding areas, which are strongly balanced by heat transport by atmospheric motions. $\mathrm{Q}_{\mathrm{SW}}$ contributes sizable amount of radiative warming of the upper troposphere of the ITCZ core region (Fig. 5e), due to absorption by enhanced cloud ice and super-cooled water (Fig. 6c, d), while inducing cooling below by cloud shielding (Fig. 5e). Comparing Fig. 5d-f, $\mathrm{Q}_{\mathrm{LW}}$ is clearly the dominant contributor in $\mathrm{Q}_{\mathrm{R}}$, providing positive feedback to warming by $\mathrm{Q}_{\mathrm{MP}}$ over the ITCZ core regions, while responsible for strong cooling near top of marine low clouds in the lower troposphere $(850-700 \mathrm{hPa}$ ) over the drier part of the MCZ and the DZ. The strong $\mathrm{Q}_{\mathrm{LW}}$ warming in the ITCZ core (Fig. 5f) is likely associated with increased trapping of longwave by increased water vapor (positive $\Delta \mathrm{RH}$ in Fig. 6a), increased cloud liquid water and ice (Fig. 6c-e), associated with strongly enhanced precipitation (Fig. 6f). The strong low-level $\mathrm{Q}_{\mathrm{LW}}$ cooling over the MCZ and the DZ (Fig. 5f) occurs near cloud 
Fig. 5 Control-minus-NoCRF height-precipitation functional relationship for $\mathbf{a} \mathrm{Q}_{\mathrm{MP}}, \mathbf{b} \mathrm{Q}_{\mathrm{DYN}}$, c $A H T, \mathbf{d} Q_{R}, \mathbf{e} Q_{S W}$ and $Q_{L W}$. Units of heating are in $\mathrm{K} \mathrm{day}^{-1}$. Contours indicate NoCRF climatology. Precipitation is in $\mathrm{mm}_{\text {day }^{-1}}, \log 10$ units

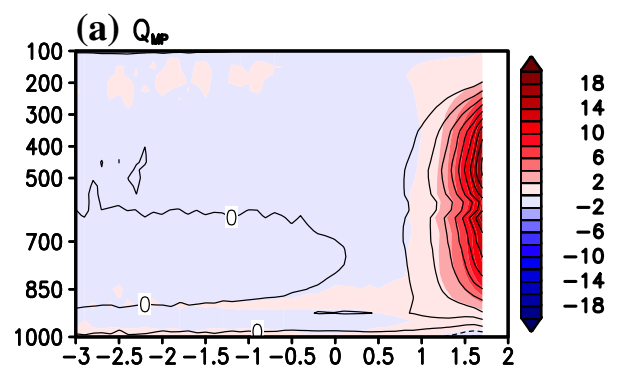

(c) $\mathrm{AHT}$
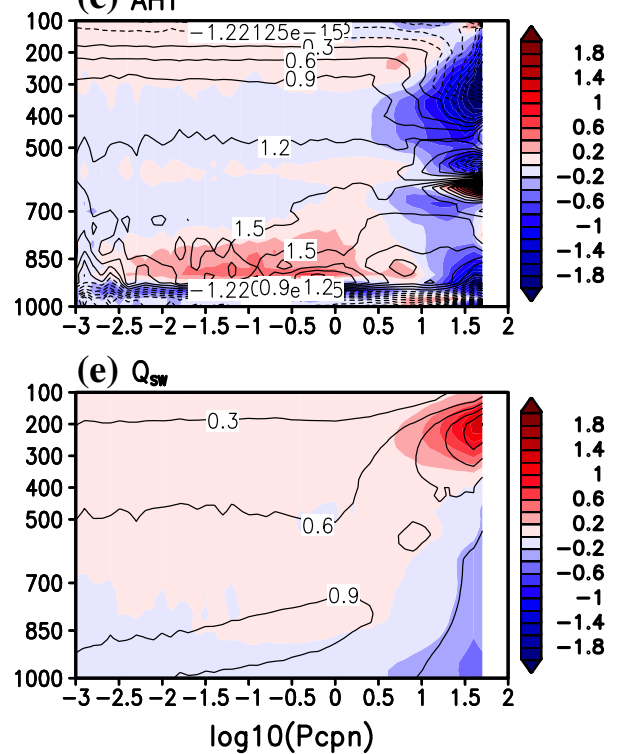

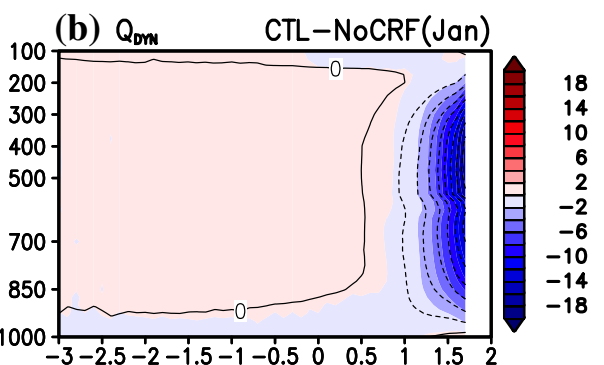

(d) $Q_{R}$
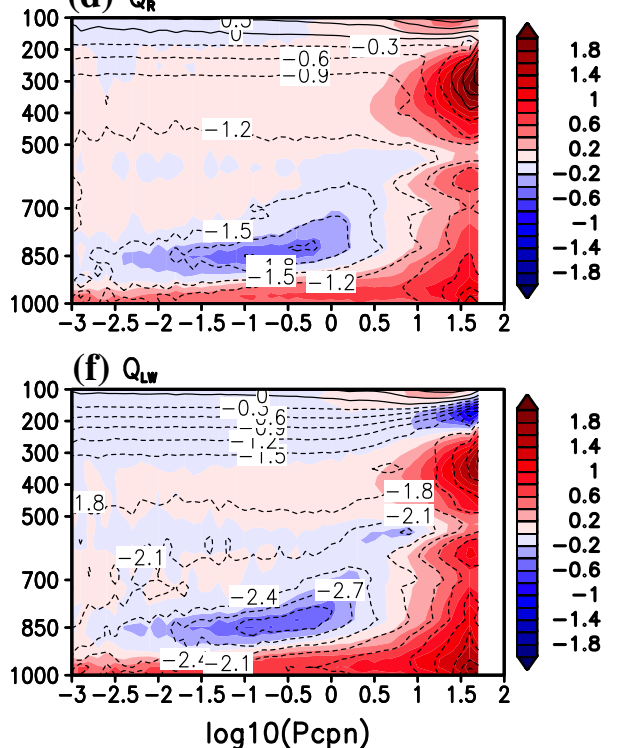

tops, in conjunction with increased dryness (negative $\Delta \mathrm{RH}$ in Fig. 6a) in the middle and upper troposphere near the edge of the ITCZ, as well as in the UTLS, and near the surface over the $\mathrm{DZ}$ where clouds and precipitation are reduced (Fig. 6d-f). Notice that while the reduction in clouds and precipitation appear small in magnitude over the DZ and MCZ (Fig. 6e, f), these two regions cover a large fractional areas ( 90\% of the tropics, see Tables 1, 2 and later discussion) the area-weighted cooling over these regions are comparable to the heating in the ITCZ region $(<10 \%$ areal coverage). In the UTLS, the strong negative $\mathrm{Q}_{\mathrm{LW}}$ stems from more cooling to space by the warmer upper atmosphere (Fig. 6b). Overall, $Q_{R}$ amplifies $Q_{M P}$ in the heavy precipitation region, while increasing the radiative cooling in the dry region, i.e. increasing diabatic heating contrast that supports a stronger overturning circulation between the wet and dry regions.

\section{July vs. January}

The same calculations and analyses described in the previous sections for January have been computed for July. As in January, the model shows an excess (20-30\%) in maximum ITCZ precipitation, compared to TRMM in July (Fig. 7a). Except for position of the ITCZ core, which is situated approximately $5-8^{\circ} \mathrm{N}$ in July, instead of $5-10^{\circ} \mathrm{S}$ in January, similar features induced by RC3I are found. These include: (1) the sharpening of the ITCZ, with suppressed precipitation on its flanks (Fig. 7b), (2) warming of the tropics and cooling of the polar regions (Fig. 7c), and (3) increased baroclinicity and enhanced midlatitude storm track activities (Fig. 7d). All the diagnostic features pertaining to Figs. 2 through 6 have been computed for July and are provided in Figs S2 through S6 in Supplementary Information (SI). Except for differences in the location of the ITCZ and regional details, all our previous discussion regarding the contributions by various processes represented in the thermodynamic energy equation, as well as functional relationships of RC3I variables with tropical precipitation for January generally hold also for July.

In the following, we further illustrate the mechanisms underlying RC3I for both seasons. First, we examine changes of the $\mathrm{HC}$ based on analysis of the meridional mass streamfunction, $\psi$ defined as:

$\psi(\emptyset, p)=2 \pi R \cos \phi \int_{0}^{p} v \frac{d p}{g}$ 
(a) $\mathrm{RH}$

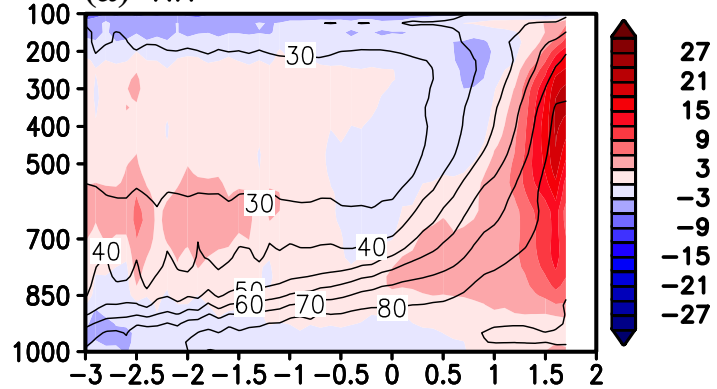

(c) Cloudlce

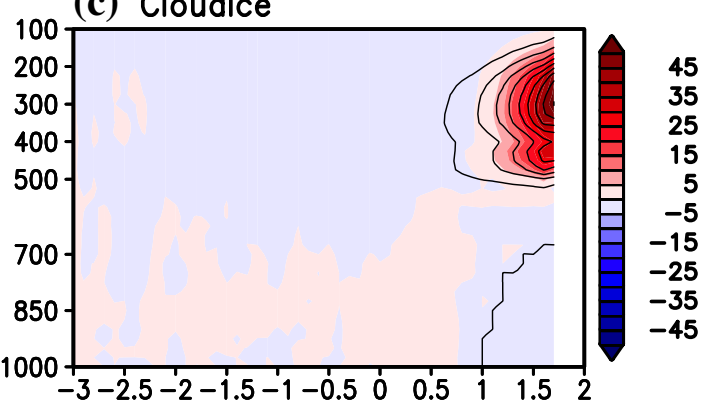

(e) Total Cloud Water \& Ice

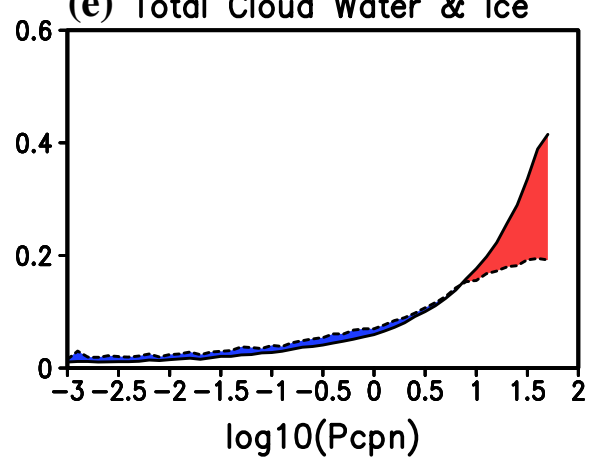

(b) Temp

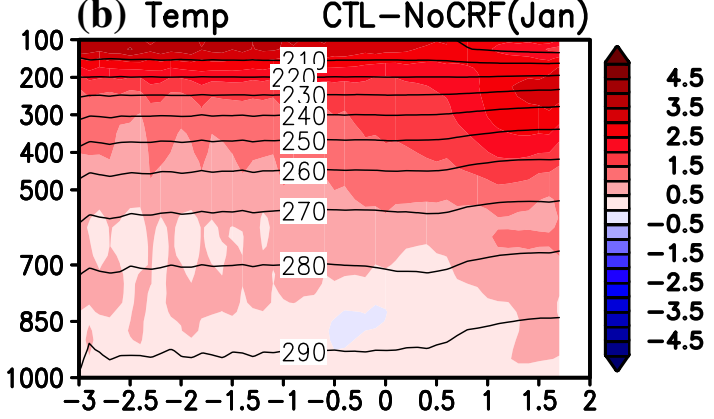

(d) CloudLiquid

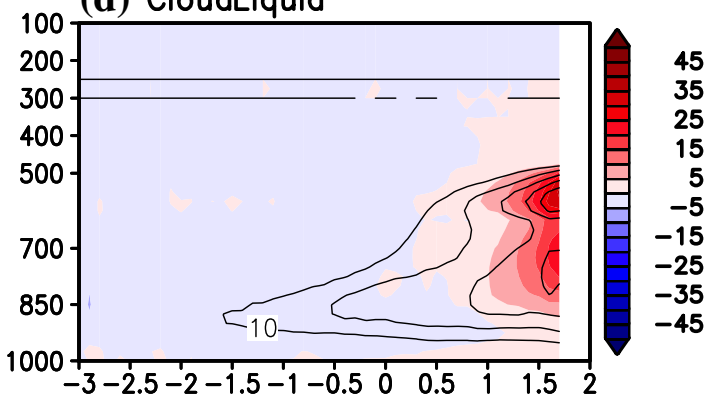

(f) Precipitation

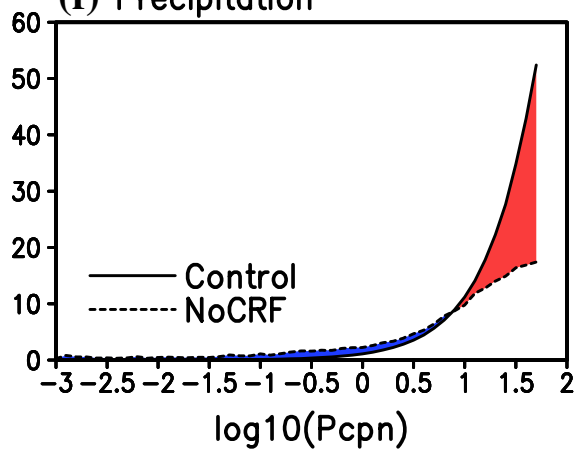

Fig. 6 Same as in Fig. 5 except for a relative humidity (\%), b tropospheric temperature (K), c cloud ice (mg/kg) and d cloud liquid (mg/kg), e total column water and ice $(\mathrm{mg} / \mathrm{kg})$, and $\mathbf{f}$ total precipitation $\left(\mathrm{mm} \mathrm{day}^{-1}\right)$. Contours indicates No-CRF climatology

where $\mathrm{R}$ is the radius of the earth, $\emptyset$, the latitude angle, and $\langle\mathrm{v}\rangle$, the zonal mean meridional velocity. During January (Fig. 8a, b), the DTS, i.e., sharpening of the ITCZ near $5-10^{\circ} \mathrm{S}$ over the warmer (southern) hemisphere, is evident in the tightly packed anomalous streamfunction lines indicating, strong low-level cross-equatorial flow from $\mathrm{NH}$ to $\mathrm{SH}$, coupled to reverse upper-level meridional flow, strong anomalous ascent near the rising center of the climatological $\mathrm{HC}$, and strong decent near $5^{\circ} \mathrm{N}$ where the climatological streamfunction is maximum and mean vertical motion is near-zero. Most of the low-level "squeeze" appears to come from the northern (cooler) hemisphere. During July (Fig. 8c, d), the DTS leads to an enhanced ITCZ over the warmer (northern) hemisphere near 5-10 N. Here, the "squeeze" seems to come from both hemispheres, with stronger contribution from the southern (cooler) hemisphere. Even though the perturbation on the zonal mean mass streamfunction is relatively small in the extratropics, atmospheric heat transport by stationary and transient eddies (see discussion pertaining to Figs. 3 and 4) play an important role in the heating and cooling of the extratropics, that could provide strong feedback to the ITCZ in the presence of cloud and water vapor radiation feedback (Kang et al. 2009; Seo et al. 2014).

Next, we explore the underlying causes for the invariance in the functional relationships between ITCZ precipitation and various cloud-scale and large-scale controls between January and July. Recent studies that have suggested the importance of convective aggregation, i.e., natural tendency of convection to cluster into smaller areas, creating larger drier and less cloudy areas between convective clusters, thus allowing more efficient cooling to space by longwave radiation (Bretherton et al. 2005; Tobin et al. 2012; Muller and Held 2012; Bony et al. 2015). Here, we explore this idea, using the mean $500 \mathrm{hPa}$ ascending motion (negative 

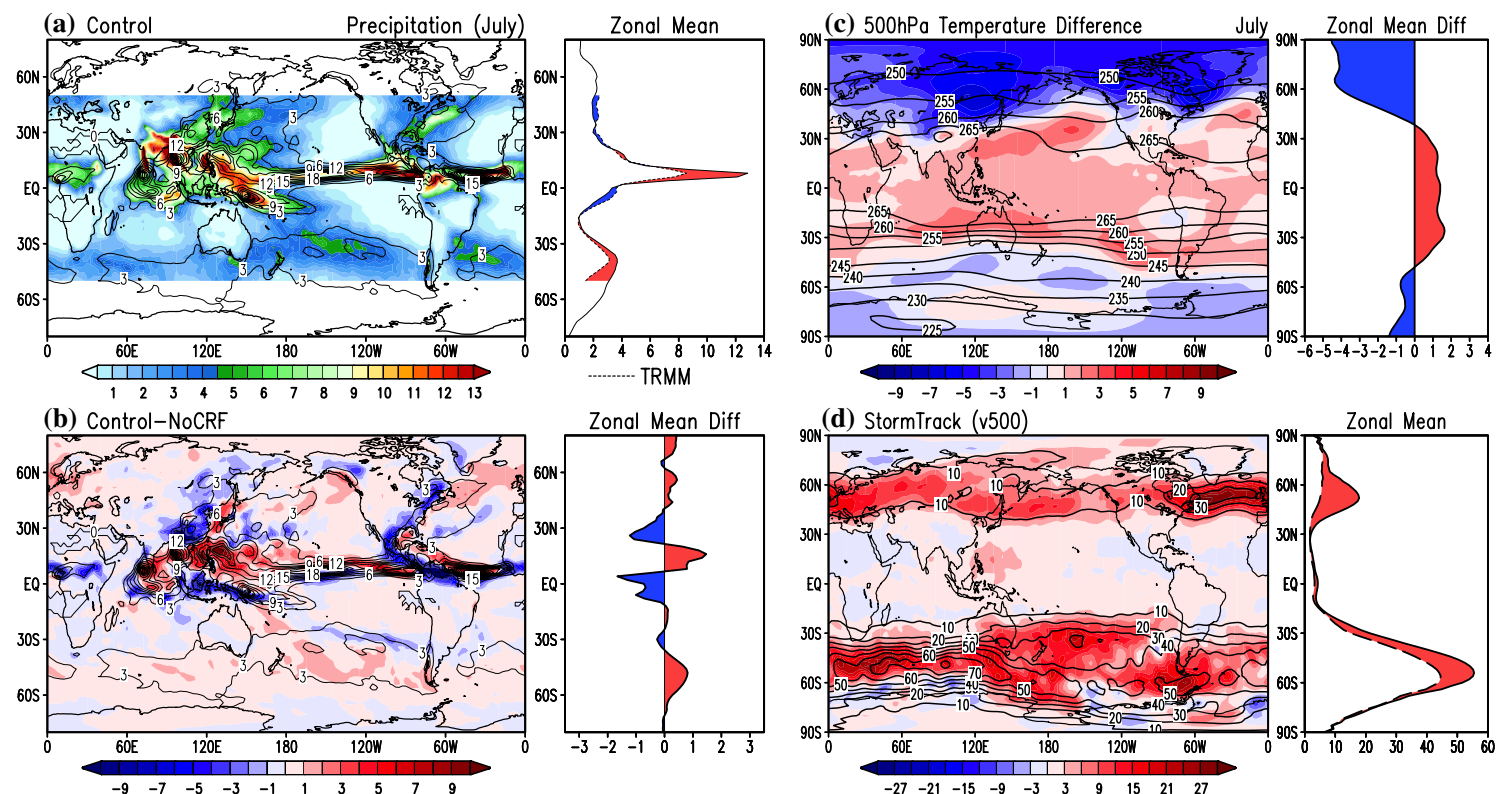

Fig. 7 Same as Fig. 1, except for July

Fig. 8 Mass streamfunction showing a NoCRF climatology (contour), b Control-NoCRF (color shaded) for January. c, d Are the same as $\mathbf{a}, \mathbf{b}$ respectively, except for July. Units are in $10^{10} \mathrm{~kg} \mathrm{~s}^{-1}$
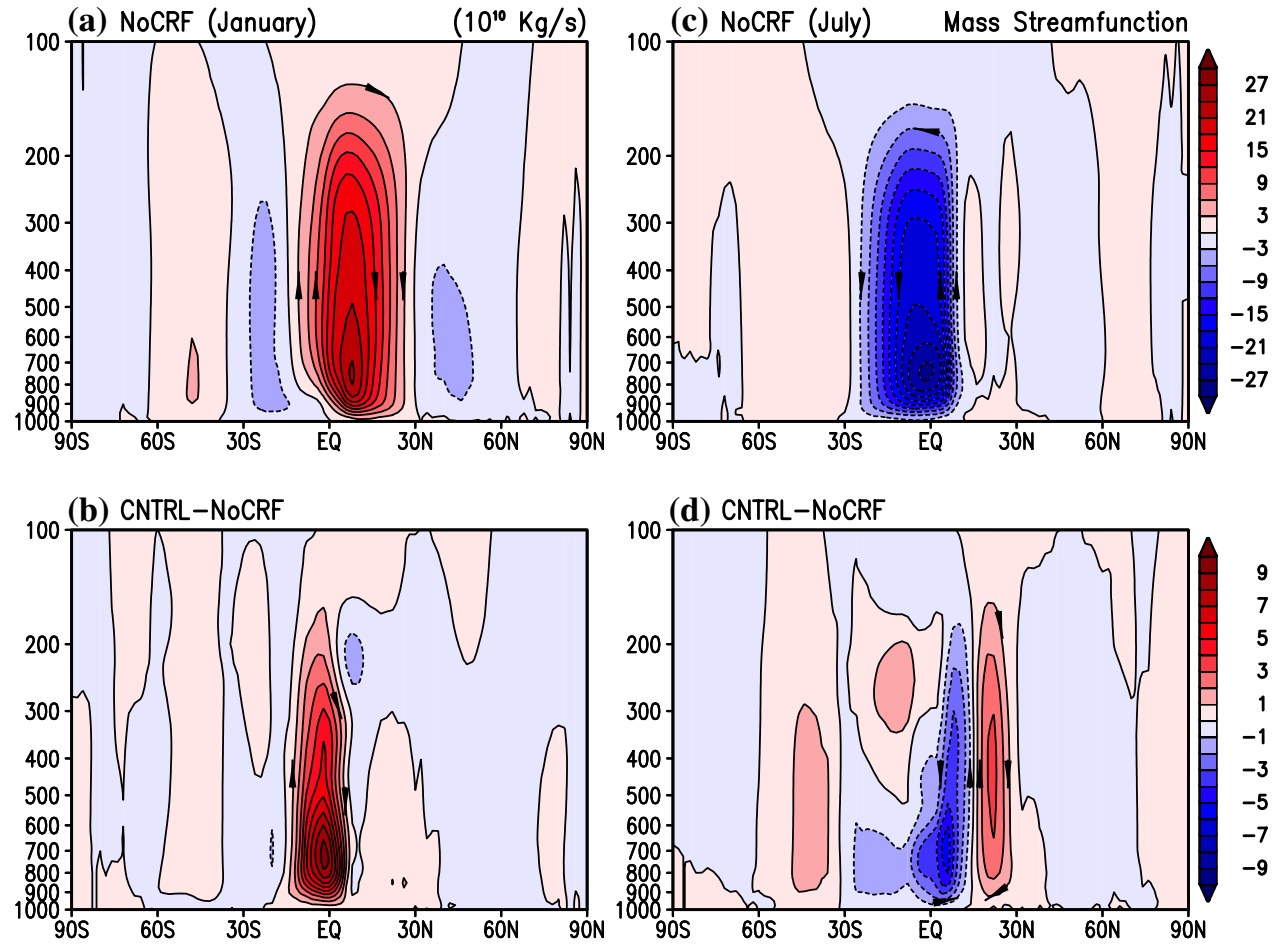

(d) CNTRL-NoCRF

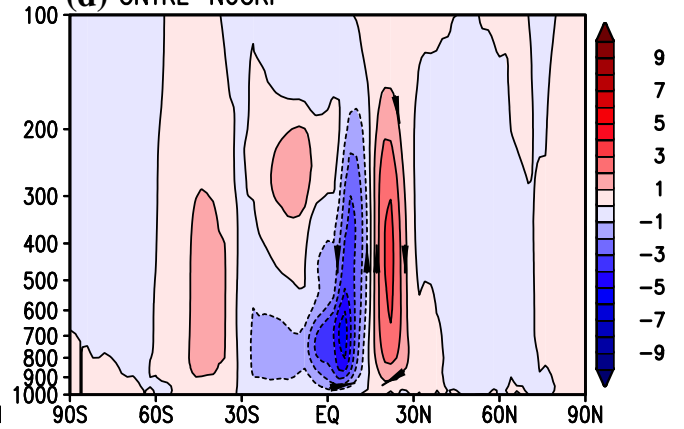

p-velocity) as a proxy of the ITCZ domain, which matches well with that defined earlier in Sect. 3.1. A comparison of the spatial pattern of ITCZ in the Control (Fig. 9a) and in NoCRF (Fig. 9b) shows that the former appears to be more organized, and concentrated over smaller areas than the latter, i.e., RC3I promotes convective aggregation. The difference map (Fig. 9c) shows that much of reduced convection, as implied by the weakened ascending motion appears to be found mostly in the MCZ near the perimeter of the ITCZ, and over land regions of South America, and South Africa, with increased ascent near the center of the ITCZ over the oceans. Overall, RC3I strongly enhances ascent in the ITCZ region, but suppresses ascent or enhances decent in the $\mathrm{MCZ}$ and DZ (Fig. 9d). On shorter (daily to pentad) time scales, 

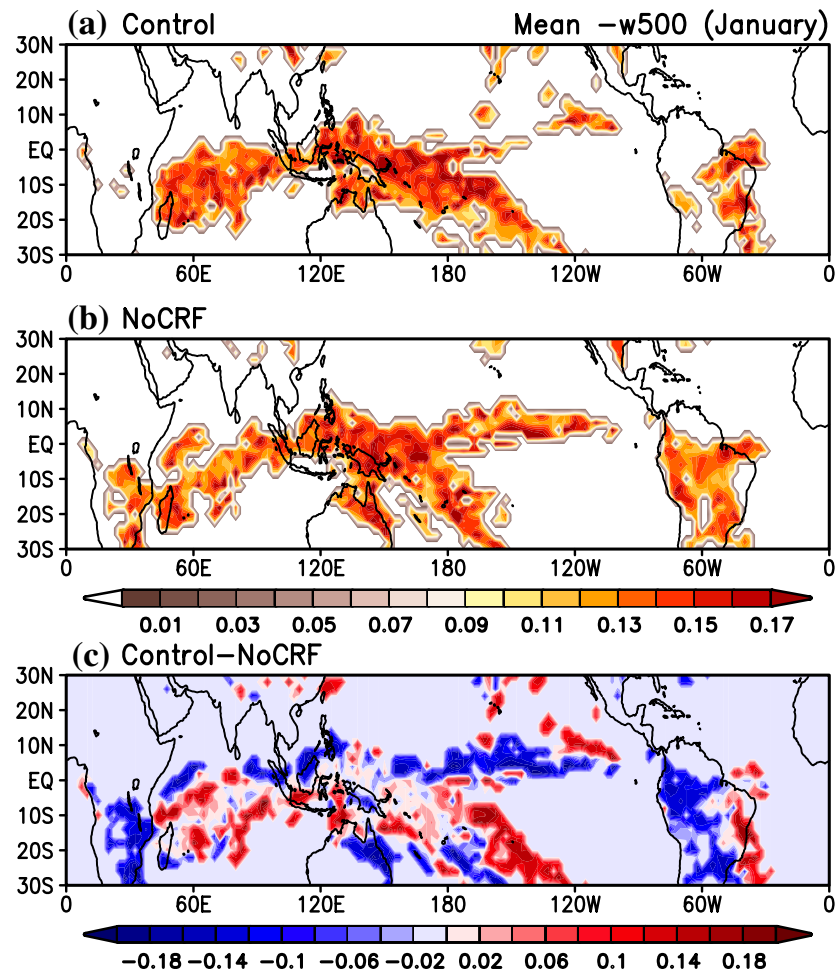

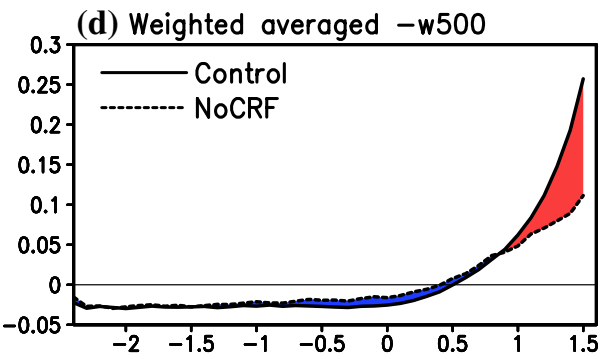

(e) Cor $=0.74 \quad$ Jan (Pentad)

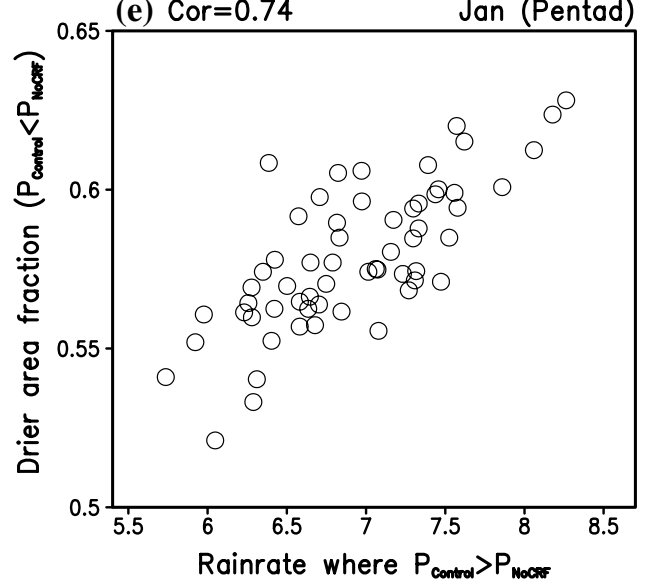

Fig. 9 January spatial distribution of $500 \mathrm{hPa}$ climatologically ascending regions for a control, b NoCRF, and c Control-minusNoCRF, d vertical motion as a function of precipitation (log
$10 \mathrm{~mm} \mathrm{day}^{-1}$ ) for Control and NoCRF respectively, and e scattered plot of increased precipitation in ITCZ region vs. area fraction where precipitation decreases heavy rainfall occurs only over small fractions of the tropics $(<10 \%)$, with large fractions of no-rain, or light rain (>90\%). A scatter plot of pentad rainfall change over regions where RC3I increases rainfall against fraction of drier area fraction where rainfall decreases (Fig. 9e), shows a strong positive correlation of $0.75, p$ value $<0.0001$, indicating an expansion of the drier area outside the ITCZ with increasing rainfall in the ITCZ. For July (Fig. 10a-d), even with a major shift of the ITCZ domain due to the seasonal change and different regional interactions compared to January, the reduced vertical ascent (suppressed convection) in the $\mathrm{MCZ}$ is still evident. The correlation between ITCZ precipitation, and fractional drier areas outside the ITCZ remain strong at $0.74, p$ value $<0.0001$ (Fig. 10d). The invariance of the correlations between precipitation rate and $\mathrm{MCZ}$ and $\mathrm{DZ}$ areal fractions between January and July suggests an intrinsic tendency for convective aggregation induced by RC3I, independent of the season.

To further illustrate the convective aggregation concept, the fractional areal coverage of the tropics $(30 \mathrm{~S}-30 \mathrm{~N})$ for four rainfall sub-regimes, i.e., $\mathrm{DZ}\left(\mathrm{P} 1<1 \mathrm{~mm} \mathrm{day}^{-1}\right)$, MCZ-dry $\left(1<\mathrm{P} 2<5 \mathrm{~mm} \mathrm{day}^{-1}\right)$, MCZ-wet $(5<\mathrm{P} 3<10$ $\left.\mathrm{mm} \mathrm{day}^{-1}\right)$ and ITCZ core $\left(\mathrm{P} 4>10 \mathrm{~mm} \mathrm{day}^{-1}\right)$, have been computed based on daily model rainfall for January and July, respectively. Additionally, a convective aggregation index (CAI) has been computed as the inverse ratio of area of the ITCZ-core (P4) to the relatively dry areas (P1and $\mathrm{P} 2)$. A large CAI signals a strong tendency for convective aggregation in the ITCZ-core, relative to the expansion of surrounding drier areas. Tables 1 and 2 shows that to a high degree of stability (relatively small standard deviation of the mean compared to the mean), the invariance of the statistics between January and July. Climatologically, for both Control and NoCRF, P1 occupies the largest fraction $(\sim 70 \%)$, and P4 the least $(\sim 10 \%)$ of the total tropical areas, and the rest of the areas ( 20\%) in the MCZ. If P2 (MCZ-dry) areas are also included as dry areas, the fraction of DZ rises to $85 \%$ over the entire tropics. The CAI shows approximately a nearly tenfold more dry areas compared to ITCZ-core areas. The effects of RC3I, as evident in the difference between the Control and NoCRF, are highly significant (p-value $<0.0001$ ) indicating an expansion of the dry areas in $\mathrm{P} 1$ and $\mathrm{P} 2(1-5 \%)$, and contraction in $\mathrm{P} 4(\sim 11 \%)$ under $\mathrm{RC} 3 \mathrm{I}$, in both January and July. The wetter regimes (P3, P4) are contracting and drier regimes (P1 and $\mathrm{P} 2)$ are expanding with nearly the same rate for January and July. An exception is for P3 (MCZ-wet), which is contracting at much faster rate in July (12.3\%) than in January (5.7\%). The reason for the difference is unknown, and maybe related to more frequent occurrence of meso-scale complexes associated with 


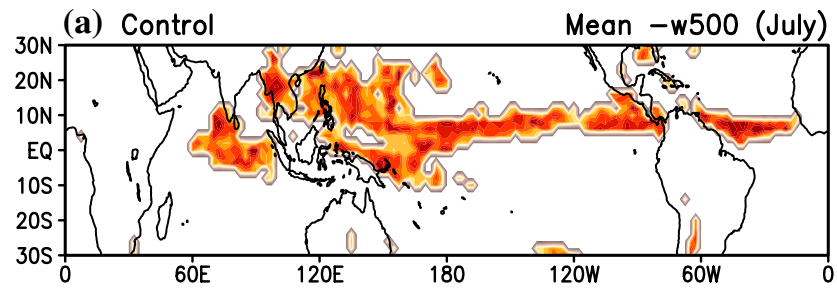

(b) NoCRF

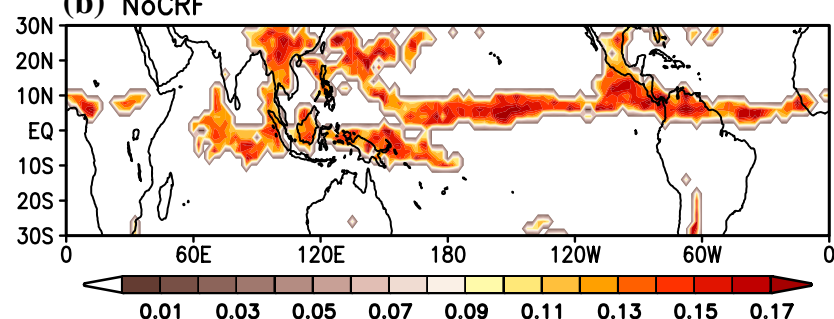

(c) Control-NoCRF

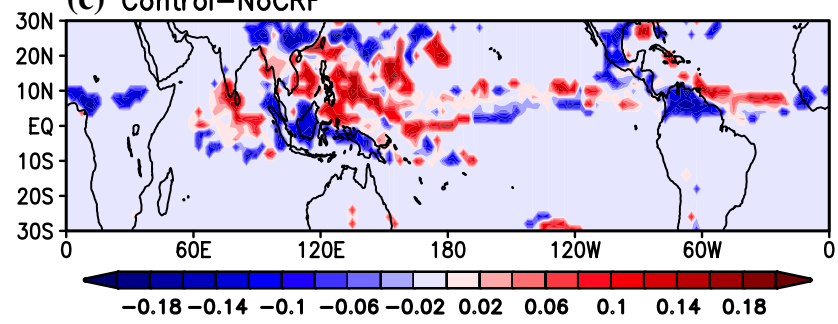

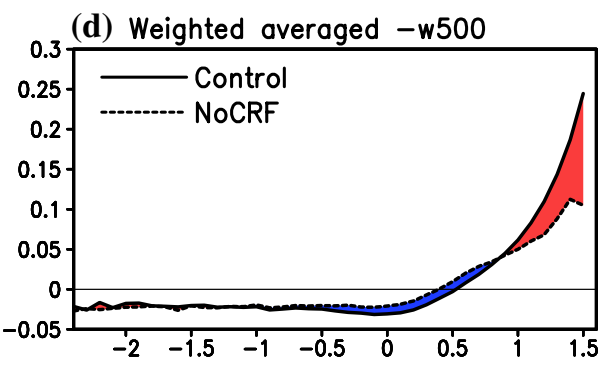

(e) Cor $=0.75$

Jul (Pentad)

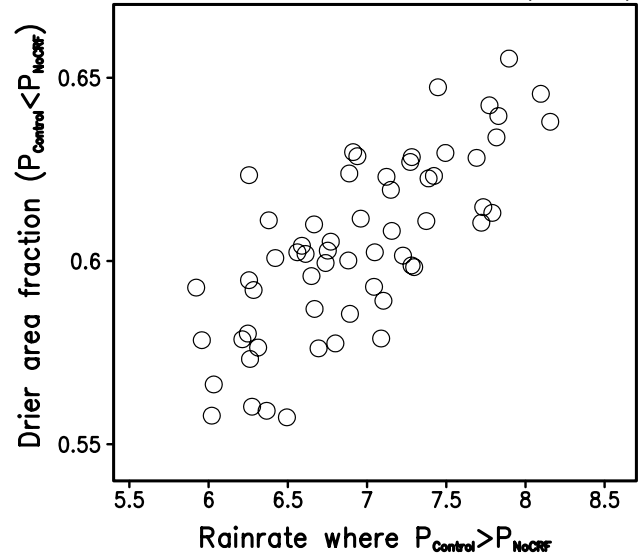

Fig. 10 Same as in Fig. 9, except for July

Table 1 January fractional areal coverage of tropical precipitation regimes defined by DZ $\left(\mathrm{P} 1<1 \mathrm{~mm} \mathrm{day}^{-1}\right)$, $\mathrm{MCZ}_{\text {-dry }}\left(1<\mathrm{P} 2<5 \mathrm{~mm}^{-1 a y}{ }^{-1}\right)$, MCZ-wet $\left(5<\mathrm{P} 3<10 \mathrm{~mm} \mathrm{day}^{-1}\right)$, and ITCZ-core $\left(\mathrm{P} 4>10 \mathrm{~mm} \mathrm{day}^{-1}\right)$, for Control, NoCRF and Control-minus-NoCRF difference $(\%$ change)

\begin{tabular}{llllllll}
\hline January & $\mathrm{P} 1$ & $\mathrm{P} 2$ & $\mathrm{P} 3$ & $\mathrm{P} 4$ & $\mathrm{P} 1 / \mathrm{P} 4$ & $\mathrm{P} 2 / \mathrm{P} 4$ & $\mathrm{CAI}=(\mathrm{P} 1+\mathrm{P} 2) / \mathrm{P} 4$ \\
\hline Control & $69.4 \pm 0.31$ & $16.6 \pm 0.19$ & $4.5 \pm 0.09$ & $9.5 \pm 0.06$ & $7.3 \pm 0.07$ & $1.7 \pm 0.02$ & $9.0 \pm 0.07$ \\
NoCRF & $68.6 \pm 0.34$ & $15.9 \pm 0.11$ & $4.7 \pm 0.13$ & $10.8 \pm 0.13$ & $6.4 \pm 0.11$ & $1.5 \pm 0.01$ & $7.8 \pm 0.12$ \\
Difference & $0.86 \pm 0.19$ & $0.69 \pm 0.14$ & $-0.27 \pm 0.08$ & $-1.28 \pm 0.11$ & $0.93 \pm 0.07$ & $0.27 \pm 0.03$ & $1.20 \pm 0.09$ \\
\% Change & 1.25 & 4.34 & -5.73 & -11.81 & 14.64 & 18.21 & 15.31 \\
\hline
\end{tabular}

Also shows are the convective aggregation index (CAI, last column), and contributions from the DZ (P1/P4), and MCS-dry (P2/P4) regimes. Uncertainties are estimated based on the standard error of the mean

Table 2 Same as in Table 1, except for July

\begin{tabular}{llllllll}
\hline July & P1 & P2 & P3 & P4 & P1/P4 & P2/P4 & CAI = (P1 + P2)/P4 \\
\hline Control & $71.2 \pm 0.21$ & $15.7 \pm 0.16$ & $4.1 \pm 0.05$ & $9.0 \pm 0.06$ & $7.9 \pm 0.07$ & $1.8 \pm 0.02$ & $9.7 \pm 0.07$ \\
NoCRF & $70.3 \pm 0.25$ & $14.8 \pm 0.21$ & $4.7 \pm 0.07$ & $10.2 \pm 0.06$ & $6.9 \pm 0.05$ & $1.5 \pm 0.02$ & $8.4 \pm 0.06$ \\
Difference & $0.90 \pm 0.35$ & $0.88 \pm 0.30$ & $-0.58 \pm 0.07$ & $-1.20 \pm 0.07$ & $1.02 \pm 0.08$ & $0.29 \pm 0.03$ & $1.32 \pm 0.08$ \\
\% Change & 1.27 & 5.94 & -12.29 & -11.79 & 14.82 & 20.07 & 15.74 \\
\hline
\end{tabular}

development of deep convection and heavy precipitation over northern hemisphere land during boreal summer under RC3I, compared to the boreal winter (Laing and Fritsch 1997; Houze 2004). Overall, the CAI shows a robust percentage increase due to RC3I for January (15.3\%) and July
(15.7\%). A further decomposition of CAI (columns 6 and 7 in Tables 1,2) shows that percentage-wise a large portion of the contraction of the ITCZ-core region is associated with the synchronized expansion of the MCZ-dry (P2) region, $18.0 \%$ and $19.3 \%$ respectively for January and July. These 
Fig. 11 Schematic showing key features and processes involving changes in ITCZ structure induced by radiation-cloud-convection-circulation interactions. Anomalous longwave cooling, upward motions, horizontal atmospheric heat transport are represented by broad arrows (blue), solid black arrows, and dashed black arrows, respectively. Size of arrow symbolizes relative magnitude of the effect

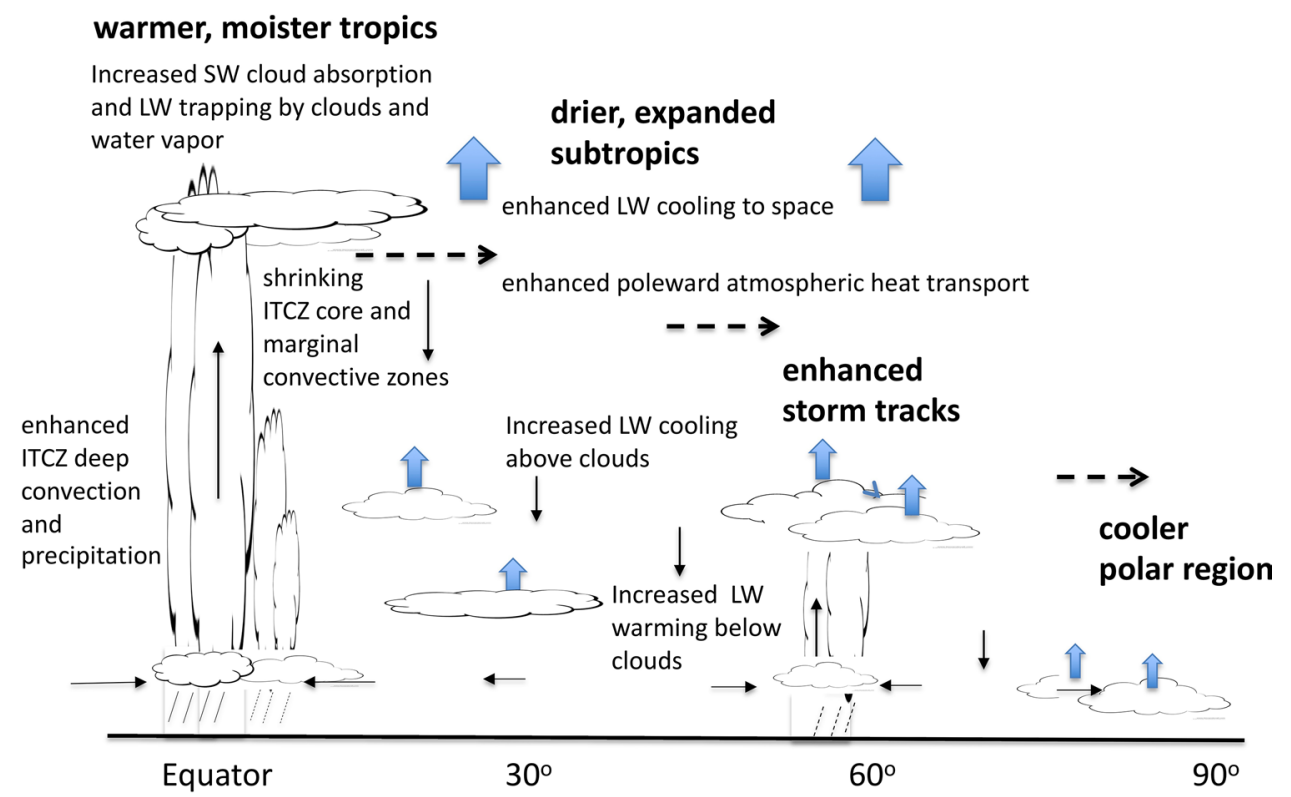

expansion of the MCZ-dry regions are consistent with the drying at the outer edge of the ITCZ core noted in Figs. 9c, and $10 \mathrm{c}$. We have carried out sensitivity calculations, adjusting the rainfall thresholds within various reasonable limits, and found the above results to be highly robust, and not sensitive to the choice of thresholds.

\section{Concluding remarks}

Using the Goddard Multi-scale Modeling Framework, we have investigated the multi-scale interactions involving radiation, clouds, convection, and circulation (RC3I) in affecting the structure and variability of the ITCZ. A 10-year control simulation experiment with full RC3I physics under prescribed sea surface forcing (2007-2016), and an anomaly experiment with the identical SST forcing but with cloud radiation feedback in the atmosphere disabled have been carried out. The results are summarized in Fig. 11, and briefly described in the following. On a global scale, RC3I leads to:

- A near-uniform warmer and moister tropics, with a sharpened ITCZ characterized by increased deep clouds, intensified precipitation, in association with increased ascent and a narrowing of the rising branch of the Hadley Circulation (HC).

- Reduced precipitation in the tropical marginal convective zones, coupled to a widened and drier descending branch of the HC, in the subtropics and mid-latitudes.

- A cooler and drier polar region, with increased baroclinicity and enhanced storm track activities, with enhanced mixed-phase clouds in mid-latitudes.
Computation of the various terms in the thermodynamic energy equation show that in the zonal mean, the anomalous tropical latent heating/cooling is strongly balanced by adiabatic processes associated with changes in vertical motions. The atmospheric heat transport (AHT, after the local balance between latent heating and adiabatic processes has been accounted for) moves heat out of the tropics towards the subtropics and to higher latitudes via a strengthened $\mathrm{HC}$, as well as increased extratropical storm track activities. Our results show the profound importance of high clouds in contributing to RC3I. In the tropics, trapping of longwave by increased high clouds and water vapor, and absorption of shortwave by increased cloud ice and water vapor in the upper troposphere provide a strong positive feedback to the warming. In the extratropics, increased high clouds induced by cloud radiation feedback maintain longwave cooling above, and warming below clouds. The changes in radiation energy are balanced by atmospheric heat transport associated with the aforementioned structural changes in the ITCZ and the large-scale circulation. Within the tropics, positive feedback between radiation effects of clouds and water vapor, and latent heating is strongest in the ITCZ core region. In the marginal convective, and dry zones, longwave radiation from marine boundary layer cloud top provides strong cooling effects. In addition, we find a strong correlation between increased daily precipitation rate, and contracting areal coverage of deep convection in the ITCZ, which is coupled to expanding drier areas in the marginal convective zones and dry zones outside the ITCZ, indicating a tendency for convective aggregation. Our results suggest the notion of "wet regions getting wetter and contracted" coupled to "dry-getting drier and expanded" as 
a fundamental way the large-scale circulation adjust to cloud radiation feedback on a global scale, in agreement with the "Deep Tropical Squeeze" hypothesis on changing structure of the ITCZ under greenhouse warming (Lau and Kim 2015). This notion is also consistent with previous studies indicating the importance of cloud radiation in intensifying and maintaining the diabatic heating contrast, between cloudy (wet) and clear (dry) regions in the mean climate (Gray and Jacobson 1977; Webster 1994; Webster and Stephens 1980) and in perturbed climate states such as El Nino-Southern Oscillation (Rädel et al. 2016; Stephens et al. 2008, 2018).

Notably, because of its ability to resolve convection near its native scales, a SP-GCM, in this case the GMMF, can provide a powerful modeling tool for better understanding of RC3I, and related climate change sciences. However, cloud resolving model (CRM) with $4 \mathrm{~km}$ resolution still cannot actually resolve clouds, but rather represent an improvement in simulation of convective processes compared to traditional convective parameterization. Additionally, the SP-GCMs are also known to possess bias of too strong tropical precipitation, probably related to limitation stemming from the 2-D nature and cyclic boundary condition of the embedding CRMs. Most important, because simulations of shallow convection and low clouds in state-of-the-art CRMs are sensitive to grid resolution (Noda et al. 2010; Muller and Held 2012), effects of subgrid turbulent moist processes still need to be included, and higher resolution CRMs, or large eddy scale (LES) models may need to be used. Finally, we note that the omission of surface fluxes feedback from the ocean and land in the present experimental design limits the application of model results to atmosphere-only cloud radiation feedback. Hence the present results, especially the quantitative aspects should be taken with caution, when compared to observations, and coupled model studies. Further studies are needed to examine how surface feedback from ocean and land may modulate the RC3I features shown here (Andrew et al. 2009; Qu and Hall 2006). As such, the present study can only be considered as providing a unifying theme underlying a number of current theories on impacts of RC3I on ITCZ maintenance and variability (e.g. Fu et al. 2002; Lintner and Neelin 2007; Kang et al. 2008, 2009; Frierson and Hwang 2012; Lau and Kim 2015; Fu 2015; Bischoff and Schneider 2016; Su et al. 2014, 2017; Byrne and Schneider 2018). This theme needs to be ascertained with more reliable presentday observations, inter-comparison with theoretical studies using aqua-planet models, as well as advanced tools such as cloud-permitting variable-resolution models, and eventually global cloud resolving coupled models.
Acknowledgements This work was supported jointly by the NASA Precipitation Measuring Mission (PMM) Grant NNX16AE45G to University of Maryland, and by the Department of Energy, Office of Science, Biological and Environmental Research. The Pacific Northwest National Laboratory is operated for the Department of Energy, by Battelle Memorial Institute under contract DE-AC05-76RL01830. Partial support was also provided by the NASA Modeling, Analysis and Prediction (MAP)

Open Access This article is distributed under the terms of the Creative Commons Attribution 4.0 International License (http://creativeco mmons.org/licenses/by/4.0/), which permits unrestricted use, distribution, and reproduction in any medium, provided you give appropriate credit to the original author(s) and the source, provide a link to the Creative Commons license, and indicate if changes were made.

\section{References}

Andrew T, Forster PM, Gregory JM (2009) A surface energy perspective on climate change. J Clim 22:2557-2570. https://doi. org/10.1175/2008JCLI2759.1

Bischoff T, Schneider T (2016) The equatorial energy balance, ITCZ position, and double-ITCZ bifurcations. J Clim 29:2997-3013

Bony et al (2015) Clouds, circulation and climate sensitivity. Nat Geosci 8:261-268. https://doi.org/10.1038/ngeo2398

Bretherton CS, Blossey PN, Khairoutdinov M (2005) An energybalance analysis of deep convective self-aggregation above uniform SST. J Atmos Sci 62:4273-4292

Broccoli AJ, Dahl KA, Stouffer RJ (2006) Response of the ITCZ to Northern Hemisphere cooling. Geophys Res Lett 33:L01702. https://doi.org/10.1029/2005GL024546

Byrne MP, Schneider T (2016) Narrowing of the ITCZ in a warming climate: Physical mechanisms. Geophys Res Lett 43:1135011357. https://doi.org/10.1002/2016g1070396

Byrne MP, Schneider T (2018) Atmospheric dynamics feedback: concept, simulations, and climate implications. J Clim 31:3249-3264. https://doi.org/10.1175/JCLI-D-17-0470.1

Byrne MP, Pendergrass AG, Rapp AD, Woodzicki KR (2018) Response of the Intertropical Convergence Zone to climate change: location, width, and strength. Curr Clim Change 4:355. https://doi.org/10.1007/s40641-018-0110-5

Charney JG, Drazin PG (1961) Propagation of planetary-scale disturbances from the lower into the upper atmosphere. J Geophys Res 66:83-109. https://doi.org/10.1029/JZ066i001p00083

Cheng A, Xu KM (2011) Improved low-cloud simulation from a multiscale modeling framework with a third-order turbulence closure in its cloud-resolving model component. J Geophys Res 116:D14101. https://doi.org/10.1029/2010JD015362

Chern JD, Tao WK, Lang SE, Li JLF, Mohr KI, Skofronick-Jackson GM, Peters-Lidard CD (2016) Performance of the goddard multiscale modeling framework with goddard microphysical schemes. J Adv Model Earth Syst 8:66-95. https://doi. org/10.1002/2015MS000469

Chou C, Neelin JD (2004) Mechanisms of global warming impacts on regional tropical precipitation. J Clim 17:2688-2701

Chou MD, Suarez MJ (1999) A shortwave radiation parameterization for atmospheric studies, Rep. NASA/TM-104606, pp. 40, NASA, Center for AeroSpace Information, Hanover, Maryland

Chou MD, Lee KT, Tsay SC, Fu Q (1999) Parameterization for cloud longwave scattering for use in atmospheric models. J Clim 12:159-169

Chou MD, Lee KT, Yang P (2002) Parameterization of shortwave cloud optical properties for a mixture of ice particle habits for 
use in atmospheric models. J Geophys Res 107:4600. https:// doi.org/10.1029/2002JD002061

Dai A (2011) Drought under global warming: a review. WIRES Clim Change 2:45065. https://doi.org/10.10002/wcc.81

Dai A (2013) Increasing drought under global warming in observations and models. Nat Clim Change 3:52-58. https://doi. org/10.1038/NCLIMAE1633

Feng S, Fu Q (2013) Expansion of global drylands under a warming climate. Atmos Chem Phys 13:10081-10094. https://doi. org/10.5194/acp-13-10081-2013

Frierson DMW, Hwang YT (2012) Extratropical influence on ITCZ shifts in slab Ocean simulations of global warming. J Clim 25:720-733. https://doi.org/10.1175/JCLI-D-11-00116.1

Fu R (2015) Global warming-accelerated drying in the tropics. Proc Natl Acad Sci 112:3593-3594. https://doi.org/10.1073/ pnas. 1503231112

Fu Q, Baker M, Hartmann DL (2002) Tropical cirrus and water vapor: an effective Earth infrared iris feedback? Atmos Chem Phys 2:31-37. https://doi.org/10.5194/acp-2-31-2002

Gray WM, Jacobson RW (1977) Diurnal variation of deep cumulus convection. Mon Weather Rev 105:1171-1188. https://doi.org/ 10.1175/1520/0493(1977)105\%3C1171:DVODCC\%3E2.0.CO;2

Gu G, Adler RF (2013) Interdecadal variability/long-term changes in global precipitation patterns during the past three decades: global warming and/or pacific decadal variability? Clim Dyn 40:3009. https://doi.org/10.1007/s00382-012-1443-8

Gu G, Adler RF, Huffman GJ (2016) Long term changes/trends in surface temperature and precipitation during the satellite era 1979-2012. Clim Dyn 46:1091. https://doi.org/10.1007/s0038 2-015-2634-x

Harrop BE, Hartman DL (2016) The role of cloud radiative heating in determining the location of the ITCZ in aqua-planet simulations. J Clim 29:2741-2763

Holton JR (2004) An introduction to dynamic meteorology, 4rd Edn. Elsevier Academic Press, Inc., Oxford. ISBN-13:978-0-12-354015-7

Hong Y, Liu G, Li JLF (2016) Assessing the radiative effects of global ice clouds based on CloudSat and CALIPSO measurements. J Clim 29:7651-7674

Houze RA (2004) Mesoscale convective systems. Rev Geophys 42:RG4003. https://doi.org/10.1029/2004rg000150

$\mathrm{Hu}$ Y, Fu Q (2007) Observed poleward expansion of the Hadley Circulation since 1979. Atmos Chem Phys 7:5229-5236

Huang et al (2017) Dryland climate change: recent progress and challenges. Rev Geophys 55:719-778. https://doi.org/10.1002/2016R G000550

Hwang YT, Frierson DMW (2013) Link between the double-intertropical convergence zone problem and cloud biases over the Southern Ocean. Proc Natl Acad Sci 110:4935-4940

IPCC (2013) The physical science basis. In: Stocker TF et al (eds) Contribution of working group I to the fifth assessment report of the intergovernmental panel on climate change. Cambridge University Press, Cambridge

Kang SM, Held IM, Frierson DM, Zhao M (2008) The response of the ITCZ to extratropical thermal forcing: idealized slab-ocean experiments with a GCM. J Clim 21:3521-3532. https://doi. org/10.1175/2007JCLI2146.1

Kang SM, Frierson DM, Held IM (2009) The tropical response to extratropical thermal forcing in an idealized GCM: the importance of radiative feedbacks and convective parameterization. J Atmos Sci 66:2812-2827

Khairoutdinov M, Randall D, DeMott C (2005) Simulations of the atmospheric general circulation using a cloud-resolving model as a superparameterization of physical processes. J Atmos Sci 62:2136-2154. https://doi.org/10.1175/JAS3453.1
Khairoutdinov M, DeMott C, Randall D (2008) Evaluation of the simulated interannual and subseasonal variability in an AMIP-style simulation using the CSU Multiscale Modeling Framework. J Clim 21:413-431. https://doi.org/10.1175/2007JCLI1630.1

Klemp JB, Wilhelmson RB (1978) The simulation of three dimensional convective storm dynamics. J Atmos Sci 35:1070-1096

Lacis AA, Hansen J (1974) A parameterization for the absorption of solar radiation in the earth's atmosphere. J Atmos Sci 31:118-133

Laing AG, Fritsch JM (1997) The global population of mesoscale convective complexes. Q J R Meteorool Soc 123:389-405

Landu K, Leunbg LR, Hagos S, Vinoj V, Rayscger SA, Ringler T, Taylor M (2014) The dependence of ITCZ structure on model resolution and dynamical core in aquaplanet simulations. J Clim 27:2375-2385

Lang S, Tao W-K, Chern JD, Wu D, Li X (2014) Benefits of a $4^{\text {th }}$ ice class in the simulated radar reflectivities of convective systems using a bulk microphysics scheme. J Atmos Sci 71:3583-3612. https://doi.org/10.1175/JAS-D-13-0330.1

Larson K, Hartmann DL (2003) Interactions among cloud, water vapor, radiation, and large-scale circulation in the tropical climate. Part I: sensitivity to uniform sea surface temperature changes. J Clim 16:1425-1440

Lau KM, Kim KM (2015) Robust responses of the Hadley circulation and global dryness form CMIP5 model $\mathrm{CO}_{2}$ warming projections. Proc Natl Acad Sci 112:3630-3635. https://doi. org/10.1073/pnas.1418682112

Lau KM, Wu HT (2007) Detecting trends in tropical rainfall characteristic, 1979-2003. Int J Climatology 27:979-988. https:// doi.org/10.1002/joc. 1454

Lau KM, Wu HT (2011) Climatology and changes in tropical oceanic rainfall characteristics inferred from Tropical Rainfall Measuring Mission (TRMM) data (1998-2009). J Geophys Res 116:D17111. https://doi.org/10.1029/2011JD015827

Lau KM, Wu HT, Kim KM (2013) A canonical response in rainfall characteristics to global warming from CMIP5 model projections. Geophys Res Lett 40:3163-3169. https://doi. org/10.1002/grl.50420

Li G, Xie S (2014) Tropical Biases in CMIP5 multimodel ensemble: the excessive equatorial pacific cold tongue and double ITCZ problems. J Clim 27:1765-1780. https://doi.org/10.1175/JCLID-13-00337.1

Li F, Rosa D, Collins WD, Wehner MF (2012) "Super-parameterization": a better way to simulate regional extreme precipitation? J Adv Model Earth Syst 4:M04002. https://doi. org/10.1029/2011MS000106

Lin J (2007) The double-ITCZ problem in IPCC AR4 coupled GCMs: ocean-atmosphere feedback analysis. J Clim 20:44974525. https://doi.org/10.1175/JCLI4272.1

Lintner BR, Neelin JD (2007) A prototype for convective margin shifts. Geophys Res Lett 34:L05812. https://doi. org/10.1029/2006GL027305

Lloyd J, Guilyardi E, Weller H (2012) The role of atmosphere feedbacks during ENSO in the CMIP3 models. Part III: the shortwave flux feedback. J Clim 25:4275-4293

Lorenz E (1967) The nature and theory of the general circulation of the atmosphere. World Meteorological Organization, Geneva

Lu J, Deser C, Reichler T (2009) Cause of the widening of the tropical belt since 1958. Geophys Res Lett 36:L03803. https://doi. org/10.1029/2008GL036076

Luo Z, Stephens GL (2006) An enhanced convection-wind-evaporation feedback in a superparameterization GCM (SP-GCM) depiction of the Asian summer monsoon. Geophys Res Lett 33:L06707. https://doi.org/10.1029/2005GL025060

Marchand R, Haynes J, Mace GG, Ackerman T, Stephens G (2009) A comparison of simulated cloud radar output from the multiscale 
modeling framework global climate model with CloudSat cloud radar observations. J Geophys Res 114:D00A20

Mauritsen T, Stevens B (2015) Missing iris effect as a possible cause of muted hydrological change and high climate sensitivity in models. Nat Geosci 8:346-351. https://doi.org/10.1038/ NGEO2414

Mohr KI, Tao WK, Chern JD, Kumar SV, Peters-Lidard CD (2013) The NASA-Goddard Multi-scale Modeling Framework-Land Information System: global land/atmosphere interaction with resolved convection. Environ Model Softw 39:103-115. https:// doi.org/10.1016/j.envsoft.2012.02.023

Muller CJ, Held I (2012) Detailed investigation of the self aggregation of convection in cloud resolving simulations. J Atmos Sci 69:2551-2565

Neelin JD, Chou C, Su H (2003) Tropical drought regions in global warming and El Niño teleconnections. Geophys Res Lett 30:2275. https://doi.org/10.1029/2003GL018625

Noda AT, Oouchi K, Satoh M, Tomita H, Iga S, Tsushima Y (2010) Importance of the subgrid-scale turbulent moist processes: cloud distribution in global cloud-resolving simulations. Atmos Res 96:208-217. https://doi.org/10.1016/j.atmos res.2009.05.007

Ogura Y, Phillips NA (1962) Scale analysis of deep and shallow convection in the atmosphere. J Atmos Sci 19:173-179

Peixoto JP, Oort AH (1992) Physics of climate, American Institute of Physics. ISBN:0-88318-712-4

Pierrehumbert RT (1995) Thermostats, radiator fins, and the local runaway greenhouse. J Atmos Sci 52:1784-1806

Pritchard MS, Somerville RCJ (2009) Assessing the diurnal cycle of precipitation in a multi-scale climate model. J Adv Model Earth Syst 1:12. https://doi.org/10.3894/JAMES.2009.1.12

Pritchard MS, Moncrieff MW, Somerville RCJ (2011) Orogenic propagating precipitation systems over the United States in a global climate model with embedded explicit convection. J Atmos Sci 68:1821-1840. https://doi.org/10.1175/2011JAS3699.1

Qu X, Hall A (2006) Assessing snow Albedo feedback in simulated climate change. J Clim 19:2617-2630. https://doi.org/10.1175/ JCLI3750.1

Rädel G, Mauritsen T, Stevens B, Dommenget D, Matei D, Bellomo K, Clement A (2016) Amplification of El Niño by cloud longwave coupling to atmospheric circulation. Nat Geosci 9:106-110. https ://doi.org/10.1038/NGEO2630

Randall DA, DA Harshvardhan Dazlich, Corsetti TG (1989) Interactions among radiation, convection, and large-scale dynamics in a general circulation model. J Atmos Sci 46:1943-1970. https://doi.org/10.1175/1520-0469(1989)046\%3c1943:IARCA $\mathrm{L} \% 3 \mathrm{e} 2.0 . \mathrm{CO} ; 2$

Randall D, Khairoutdinov M, Arakawa A, Grabowski W (2003) Breaking the cloud parameterization deadlock. Bull Am Meteorol Soc 84:1547-1564

Raymond DJ, Zeng X (2005) Modeling tropical atmospheric convection in the context of the weak temperature gradient approximation. Q J R Meteorol Soc 131:1301-1320

Satoh M, Matsuno T, Tomita H, Miura H, Nasuno T, Iga S (2008) Nonhydrostatic icosahedral atmospheric model (NICAM) for global cloud resolving simulations. J Comput Phys 227:3486-3514

Seidel DJ, Randel WJ (2007) Recent widening of the tropical belt: evidence from tropopause observations. J Geophys Res 112:D20113. https://doi.org/10.1029/2007JD008861

Seo J, Kang SM, Frierson DM (2014) Sensitivity of intertropical convergence zone movement to the latitudinal position of thermal forcing. J Clim 27:3035-3042

Shen BW, Nelson B, Cheung S, Tao WK (2013) Improving NASA's Multiscale Modeling Framework for tropical cyclone climate study. Comput Sci Eng 15:56-67. https://doi.org/10.1109/ MCSE. 2012.90
Shonk JKP, Guilyardi E, Toniazzo T, Woolnough SJ, Stockdale $\mathrm{T}$ (2018) Identifying causes of Western Pacific ITCZ drift in ECMWF System 4 hindcasts. Clim Dyn 50:939-954

Simmons AJ (1974) Planetary-scale disturbances in the polar winter stratosphere. Q J R Meteorol Soc 100:76-108. https://doi. org/10.1002/qj.49710042309

Slingo JM, Slingo A (1988) The response of the general circulation model to longwave radiative forcing, I: introduction and initial experiment. Q J R Meteorol Soc 114:1027-1062. https://doi. org/10.1002/qj.49711448209

Slingo JM, Slingo A (1991) The response of the general circulation model to longwave radiative forcing, II: further experiment. Q J R Meteorol Soc 117:333-364. https://doi.org/10.1002/qj.49711 749805

Sobel AH, Nilsson J, Polvani LM (2001) The weak temperature gradient approximation and balanced tropical moisture waves. J Atmos Sci 58:3650-3665

Stephens GL (2004) Cloud feedback in the climate system: a critical Review. J Clim. 18:232-273

Stephens GL, Webster PJ (1979) Sensitivity of radiative forcing to variable cloud and moisture. J Atmos Sci 36:1542-1556. https ://doi.org/10.1175/1520-0469(1979)036\%3c1542:SORFT $\mathrm{V} \% 3 \mathrm{e} 2.0 . \mathrm{CO} ; 2$

Stephens GL, van den Heever S, Pakula LA (2008) Radiative convective feedback in idealized states of radiative-convective equilibrium. J Atmos Sci 65:3899-3916. https://doi.org/10.1175/2008J AS2524.1

Stephens GL, Hakuba MZ, Webb MJ, Lebsock M, Yue Q, Kahn BH et al (2018) Regional intensification of the tropical hydrological cycle during ENSO. Geophys Res Lett 45:4361-4370. https:// doi.org/10.1029/2018GL077598

Su H, Jiang JH, Zhai C, Shen T, Neelin JD, Stephens GL, Yung Y (2014) Weakening and strengthening structures in the Hadley Circulation change under global warming and implications for cloud response and climate sensitivity. J Geophys Res 119:57875805. https://doi.org/10.1002/2014JD021642

Su H, Jiang JH, Neelin JD, Shen TJ, Zhai C, Yue Q, Wang Z, Huang L, Choi YS, Stephens GL, Yung YL (2017) Tightening of the tropical ascent and high clouds key to precipitation change in a warmer climate. Nat Commun 8:15771. https://doi.org/10.1038/ ncomms 15771

Talib J, Woolnough SJ, Klingaman NP, Holloway CE (2018) The role of the cloud radiative effect in the sensitivity of the Intertropical Convergence Zone to convective mixing. J Clim 31:6821-6838

Tan J, Jakob C, Rossow W, Tselioudis G (2015) Increases in tropical rainfall driven by increases in frequency o organized deep convection. Nature 519:451-454

Tao WK, Chern J (2017) The impact of mesoscale convective systems on global precipitation: a modeling study. J Adv Model Earth Syst 9:790-809. https://doi.org/10.1002/2016MS000836

Tao W-K, Chern J, Atlas R, Randall D, Lin X, Khairoutdinov M, Li JL, Waliser DE, Hou A, Peters-Lidard C, Lau KM, Simpson J (2009) Multi-scale modeling system: development, applications and critical issues. Bull Am Meteorol Soc 90:515-534

Tao W-K, Lang S, Zeng X, Li X, Matsui T, Mohr K, Posselt D, Chern J, Peters-Lidard C, Norris P, Kang IS, Choi I, Hou A, Lau KM, Yang YM (2014) The Goddard Cumulus Ensemble model (GCE): improvements and applications for studying precipitation processes. Atmos Res 143:392-424

Tao W-K, Wu D, Lang S, Chern J, Fridlind A, Peters-Lidard C, Matsui T (2016) High-resolution model simulations of MC3E, deep convective-precipitation systems: comparisons between Goddard microphysics schemes and observations. J Geophys Res 121:1278-1306. https://doi.org/10.1002/2015JD023986 
Tian B (2015) Spread of model climate sensitivity linked to doubleIntertropical Convergence Zone bias. Geophys Res Lett 42:41334141. https://doi.org/10.1002/2015GL064119

Tobin I, Bony S, Roca R (2012) Observational evidence for relationships between the degree of aggregation of deep convection, water vapor, surface fluxes, and radiation. J Clim 25:6885-6904

Voigt A, Shaw TA (2015) Circulation response to warming shaped by radiative change of cloud and water vapor. Nat Geosci 8:102-106

Voigt A, Stevens B, Bader J, Mauritsen T (2014) Compensation of hemispheric albedo asymmetries by shifts of the ITCZ and tropical clouds. J Clim 27:1029-1045

Wallace JM, Hobbs PV (1977) Atmospheric sciences: an introduction survey. Academic, New York

Webster PJ (1994) The role of hydrological processes in oceanatmosphere interactions. Rev Geophys 32:427-476. https://doi. org/10.1029/94RG01873

Webster PJ, Stephens GL (1980) Tropical upper-tropospheric extended clouds: inferences from winter MONEX. J Atmos Sci 37:15211541. https://doi.org/10.1175/1520-0469-37.7.1521

Wodzicki KR, Rapp AD (2016) Long-term characterization of the Pacific ITCZ using TRMM, GPCP, and ERA-Interim. J Geophys Res Atmos 121:3153-3170. https://doi.org/10.1002/2015J D024458
Xiang B, Zhao M, Held IM, Golaz JC (2017) Predicting the severity of spurious "double ITCZ" problem in CMIP5 coupled models from AMIP simulations. Geophys Res Lett 44:1520-1527. https ://doi.org/10.1002/2016GL071992

Zhang GJ, Wang H (2006) Toward mitigating the double ITCZ problem in NCAR CCSM3. Geophys Res Lett 33:L06709. https://doi. org/10.1029/2005GL025229

Zhang K, Randel WJ, Fu R (2017) Relationships between outgoing longwave radiation and diabatic heating in reanalysis. Clim Dyn 49:2911-2929. https://doi.org/10.1007/s00382-016-3501-0

Zhao M (2014) An investigation of the connections among convection, clouds, and climate sensitivity in a global climate model. J Clim 27:1845-1862. https://doi.org/10.1175/JCLI-D-13-00145.1

Zhou Y, Xu KM, Sud Y, Betts A (2011) Recent trends of the tropical hydrological cycle inferred from Global Precipitation Climatology Project and International Satellite Cloud Climatology Project data. J Geophys Res 116:D09101. https://doi.org/10.1029/2010J D015197

Publisher's Note Springer Nature remains neutral with regard to jurisdictional claims in published maps and institutional affiliations. 